\title{
On the location of dayside magnetic reconnection during an interval of duskward oriented IMF
}

\author{
J. A. Wild ${ }^{1}$, S. E. Milan ${ }^{2}$, J. A. Davies ${ }^{3}$, M. W. Dunlop ${ }^{3}$, D. M. Wright ${ }^{2}$, C. M. Carr ${ }^{4}$, A. Balogh ${ }^{4}$, H. Rème ${ }^{5}$, \\ A. N. Fazakerley ${ }^{6}$, and A. Marchaudon ${ }^{6, *}$ \\ ${ }^{1}$ Dept. of Communication Systems, Lancaster University, Lancaster, LA1 4WA, UK \\ ${ }^{2}$ Dept. of Physics \& Astronomy, University of Leicester, Leicester, LE1 7RH, UK \\ ${ }^{3}$ Rutherford Appleton Laboratory, Didcot, Oxfordshire, OX11 0QX, UK \\ ${ }^{4}$ Blackett Laboratory, Imperial College, London SW7 2BZ, UK \\ ${ }^{5}$ CESR/CNRS, 9 Avenue du Colonel Roche BP 4346, 31028 Toulouse, Cedex 4, France \\ ${ }^{6}$ Mullard Space Science Laboratory, University College London, Holmbury St. Mary, Dorking, Surrey RH5 6NT, UK \\ * now at: LPCE/CNRS and Université d'Orléans, Orléans, France
}

Received: 11 October 2006 - Revised: 2 January 2007 - Accepted: 22 January 2007 - Published: 1 February 2007

\begin{abstract}
We present space- and ground-based observations of the signatures of magnetic reconnection during an interval of duskward-oriented interplanetary magnetic field on 25 March 2004. In situ field and plasma measurements are drawn from the Double Star and Cluster satellites during traversals of the pre-noon sector dayside magnetopause at low and high latitudes, respectively. These reveal the typical signatures of flux transfer events (FTEs), namely bipolar perturbations in the magnetic field component normal to the local magnetopause, enhancements in the local magnetic field strength and mixing of magnetospheric and magnetosheath plasmas. Further evidence of magnetic reconnection is inferred from the ground-based signatures of pulsed ionospheric flow observed over an extended interval. In order to ascertain the location of the reconnection site responsible for the FTEs, a simple model of open flux tube motion over the surface of the magnetopause is employed. A comparison of the modelled and observed motion of open flux tubes (i.e. FTEs) and plasma flow in the magnetopause boundary layer indicates that the FTEs observed at both low and high latitudes were consistence with the existence of a tilted Xline passing through the sub-solar region, as suggested by the component reconnection paradigm. While a high latitude Xline (as predicted by the anti-parallel description of reconnection) may have been present, we find it unlikely that it could have been responsible for the FTEs observed in the pre-noon sector under the observed IMF conditions. Finally, we note that throughout the interval, the magnetosphere was bathed in ULF oscillations within the solar wind electric field. While no one-to-one correspondence with the pulsed reconnection rate suggested by the ground-based observation of pulsed
\end{abstract}

Correspondence to: J. A. Wild

(j.wild@lancaster.ac.uk) ionospheric flow has been demonstrated, we note that similar periodicity oscillations were observed throughout the solar wind-magnetosphere-ionosphere system. These findings are consistent with previously proposed mechanisms of solar wind modulation of the dayside reconnection rate.

Keywords. Magnetospheric physics (Energetic particles, precipitating; Magnetopause, cusp, and boundary layers)

\section{Introduction}

As one of the primary mechanisms by which solar wind energy, momentum and mass enter the terrestrial magnetosphere, magnetic reconnection at the dayside magnetopause is arguably the most significant factor influencing solar wind-magnetosphere-ionosphere coupling. However, in the decades since the "open" magnetosphere was first proposed by Dungey (1961) and the signatures of transient reconnection were first observed in situ (Haerendel et al., 1978; Russell and Elphic, 1978, 1979), debate has continued regarding the likely location of the reconnection site(s) under given interplanetary magnetic field (IMF) conditions.

While magnetic reconnection is often described as occurring at locations where the magnetospheric and magnetosheath fields are aligned in an anti-parallel orientation (Dungey, 1961), it is now generally accepted that reconnection will occur at some location on the magnetopause for any IMF configuration. In the ubiquitous southward IMF paradigm, reconnection occurs at a line (often known as the reconnection "X-line") spanning the dayside magnetopause along the magnetic equator. Under IMF conditions with a strong $B_{Y}$ (dusk-dawn) component, the $\mathrm{X}$-line divides in the noon sector producing two distinct reconnection lines, one in

Published by Copernicus GmbH on behalf of the European Geosciences Union. 
each hemisphere (e.g. Crooker, 1979; Luhmann et al., 1984). Alternatively, it has been proposed that magnetic reconnection can occur in the sub-solar region - the region where the magnetosheath field first comes into contact with the magnetopause - for almost any IMF orientation as long as there is a sufficiently large magnetic shear across the boundary and the IMF has a southward directed component (Gonzalez and Mozer, 1974). Such "component reconnection", X-lines would be expected to pass through the sub-solar point and to be tilted relative to the equator. The orientation of the $\mathrm{X}$ line is given by the bisector between the magnetosheath and geomagnetic fields at the magnetopause.

More recently, investigations during intervals dominated by a strong IMF $B_{Y}$ (dusk-dawn) component have revealed reconnection scenarios quite different from the traditional southward IMF paradigm (e.g. Fedorov et al., 2001). Modelling of solar wind plasma entry into the magnetosphere and ionosphere has lead to the development of the "double cusp" concept: one cusp at lower latitude near noon and one cusp at higher latitude. Observational evidence for the double cusp comes mainly from low altitude satellite measurements (e.g. Wing et al., 2001) with the double cusp's latitudinal width and equatorward boundary apparently controlled by the magnitude of the IMF $B_{Y}$ component (Wing et al., 2005). Meanwhile, reconnection on the flank magnetopause (Khotyaintsev et al., 2004) and the combined effects of simultaneous dayside and lobe reconnection on magnetospheric and ionospheric convection have also been reported under strongly $B_{Y}$ dominated IMF conditions (Sandholt and Farrugia, 2006).

Combined space- and ground-based investigations have made a significant contribution to our understanding of the dayside reconnection process (the reader is directed to Wild et al., 2001; Amm et al., 2005, and references therein). Such techniques are particularly useful since ground-based experiments can measure the azimuthal extent of the Xline by tracking the ionospheric signatures of flux transfer, while space-based instruments can make detailed in situ measurements of individual flux transfer events (FTEs). However, it should be noted that the comparison of space- and ground-based measurements relies upon accurate magnetic field mapping between the ionosphere and magnetosphere. Even if the chosen magnetic field model is assumed to be totally accurate, it is still necessary to examine low-altitude plasma measurements in order to estimate the distance of the measurement point from the reconnection site along the field line if the intention is to discriminate between a possible low, mid, or high latitude reconnection site (e.g. Trattner et al., 2006). Given the size of the dayside magnetopause and the sparsity of available satellites, accurately tracing a newlyopened flux tube back to the reconnection site from which it originated is a non-trivial undertaking.

The expected motion of newly-reconnected field lines emerging from either anti-parallel or component reconnection X-lines have been modelled in 2-D by Cowley and
Owen (1989) and in 3-D by Cooling et al. (2001). Recently, these models have been used in conjunction with space- and ground-based measurements in order to constrain the location of the X-line based upon the in situ and remotely-sense signatures of reconnection (e.g. Dunlop et al., 2005; Wild et al., 2005a). However, these studies have concentrated on intervals of southward oriented IMF - conditions when both the anti-parallel and component reconnection descriptions of reconnection place the $\mathrm{X}$-line in the vicinity of the sub-solar dayside magnetopause. Below, we shall consider the location of the reconnection X-line during a prolonged interval of relatively steady duskward-pointing interplanetary magnetic field. The observations shall be drawn from an interval on 25 March 2004, data first summarised in Wild et al. (2005b) in one of the first studies to exploit data from the Cluster and Double Star satellite missions in coordination with groundbased measurement. However, Wild et al. (2005b) failed to identify the likely position of the reconnection site under the prevailing duskward IMF configuration, hence the motivation for this re-investigation.

\section{Instrumentation}

The ESA Cluster mission (Escoubet et al., 1997, 2001) comprises four identically instrumented satellites flying in close formation in highly elliptical $\left(19.7 / 4.0 R_{E}\right)$ polar orbits. Launched in 2000, this mission was augmented in 2004/5 by the launch of the ESA/China National Space Administration pair of Double Star satellites (Liu et al., 2005). These spacecraft, instrumented with a subset of the Cluster payload, were injected into elliptical equatorial $\left(14.5 / 1.1 R_{E}\right)$ and polar (7.1/1.1 $\left.R_{E}\right)$ orbits such that the Cluster and Double Star orbital planes remain approximately aligned. During the interval investigated below (25 March 2004), only the equatorial Double Star spacecraft was in operation.

Cluster and Double Star observations of the local magnetic field, ion and electron populations employed in this study are provided by the fluxgate magnetometer (FGM; see Balogh et al., 1997, 2001; Carr et al., 2005), Cluster ion spectrometry (CIS; see Rème et al., 1997, 2001, 2005), and plasma electron and current (PEACE: see Johnstone et al., 1997; Owen et al., 2001; Fazakerley et al., 2005) experiments, respectively. The FGM data have been analysed at a temporal resolution equal to the spin period of the spacecraft $(\sim 4 \mathrm{~s}$ for both Cluster and Double Star). The CIS experiment measures the three-dimensional ion distribution up to energies of $\sim 38 \mathrm{keV} / \mathrm{e}$, yielding the total ion number density and velocity moments at spin resolution and full pitch angle distributions every spin in the case of Cluster and every second spin in the case of Double Star. The PEACE instrument measures the electron pitch angle distribution between energies of $0.7 \mathrm{eV}-28 \mathrm{keV} / \mathrm{e}$, yielding the total electron number density and velocity moments and gyrotropic electron pitch angle distributions at spin resolution. 

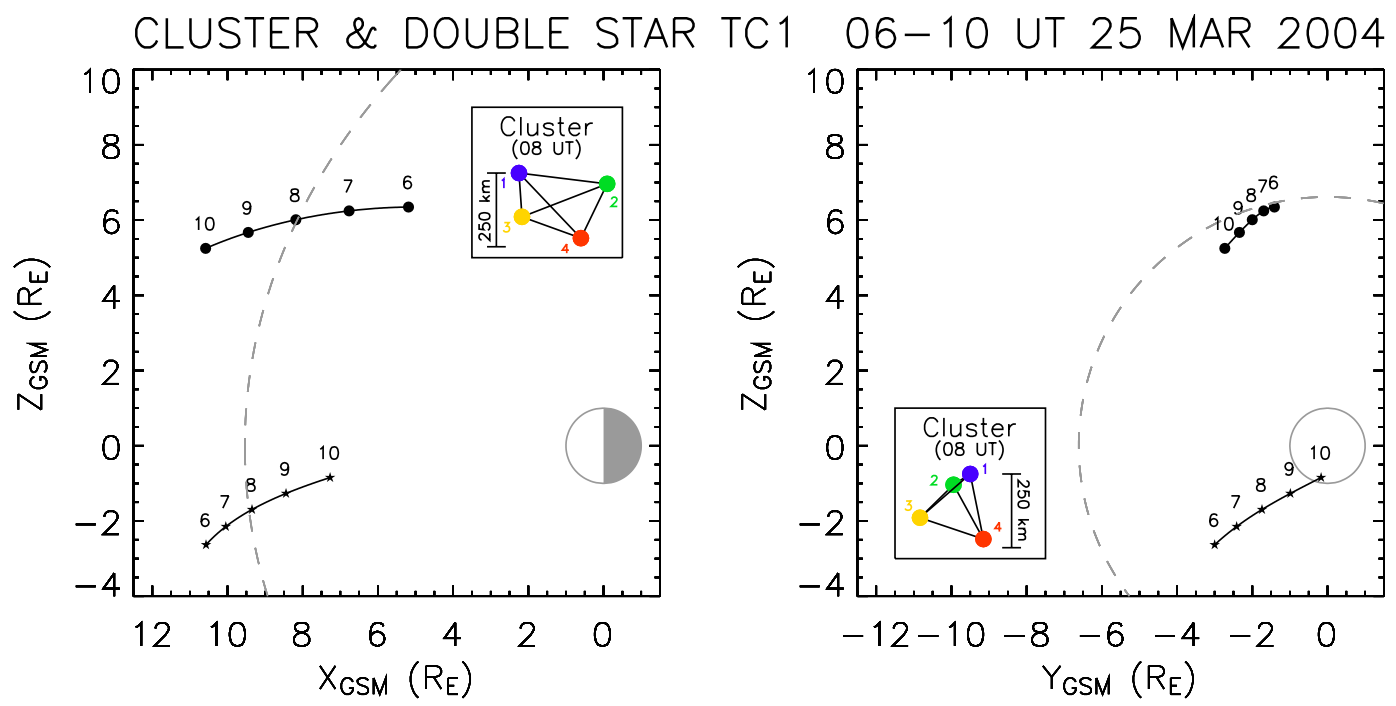

Fig. 1. The locations of the Double Star TC1 and Cluster spacecraft projected into the GSM $X-Z$ and $Y$ - $Z$ planes (left- and right-hand panels respectively) during the the interval 06:00-10:00 UT on 25 March 2004. The positions of the TC1 and Cluster 1 spacecraft are indicated at $1 \mathrm{~h}$ intervals (stars and circles respectively) and labelled according to universal time. In each figure, the tetrahedral configuration of the four Cluster spacecraft at 08:00 UT is shown in the inset.

During March 2004, the Cluster orbital plane was such that the spacecraft passed through perigee in the midnight sector and apogee in the noon sector solar wind. Figure 1 shows the motion of the Cluster and equatorial Double Star spacecraft during the interval 06:00-10:00 UT on 25 March 2004. Throughout this paper, we shall refer to the four Cluster spacecraft by using the abbreviations C1, C2, C3 and C4 . Similarly, we shall refer to the equatorial Double Star spacecraft by its designator, TC1. The left-hand panel presents the location of the $\mathrm{C} 1$ and TC1 spacecraft at hourly intervals, projected into the GSM $X-Z$ plane. The inset shows the configuration of the four Cluster spacecraft at 08:00 UT when projected into the same plane. The right-hand panel shows the spacecraft projected in the GSM $Y-Z$ plane during the same interval. The location of a Shue et al. (1997) model magnetopause, parameterised with solar wind conditions appropriate for 08:00 UT, is indicated in both panels. In the left-hand panel, a cut through the magnetopause in the $Y=-2 R_{E}$ plane is indicated by the dashed grey line (corresponding to the approximate $Y$ position at which Cluster and Double Star encountered the boundary). Similarly, in the right-hand panel, the radius of the magnetopause in the $X=+8 R_{E}$ plane is shown corresponding to the approximate $X$ position at which the Cluster spacecraft encountered the boundary). As indicated in Fig. 1, during this interval TC1 was moving on an trajectory which traversed the post-noon sector low latitude magnetopause, slightly southward of the GSM equatorial plane. Meanwhile, the quartet of Cluster spacecraft crossed the magnetopause on an outbound trajectory in the post-noon sector at higher northerly latitudes. As we shall demonstrate below, the magnetopause crossings by
TC1 and Cluster did not occur simultaneously; TC1 entered the magnetopause just prior to $\sim$ 07:00 UT while Cluster exited shortly before $\sim 08: 00$ UT.

In situ observations of the solar wind and IMF were provided by the Advanced Composition Explorer (ACE) spacecraft (Stone et al., 1998), which was located $\sim 225 R_{E}$ upstream from the Earth. Magnetic field and plasma data are provided by the magnetic fields (MAG) experiment (Smith et al., 1998) and the solar wind electron, proton, and alpha monitor (SWEPAM) (McComas et al., 1998), respectively. Unfortunately, during the interval of interest, no solar wind plasma density data were available from the SWEPAM instrument.

Figure 2 shows the arrangement of the main ground-based instruments used in this study presented in a magnetic local time/magnetic latitude coordinate system. Specifically, this figure shows the situation at 07:30 UT on 25 March 2004. Ionospheric observations are drawn from elements of the SuperDARN array of coherent scatter radars (Greenwald et al., 1995) and the European Incoherent Scatter (EISCAT) radar association. We shall present detailed measurements from the CUTLASS (Co-operative UK Twin-Located Auroral Sounding Systems) pair of SuperDARN radars located at Hankasalmi, Finland and Pykkvibær, Iceland (Lester et al., 2004). These radars transmit high-frequency (typically $10-12 \mathrm{MHz}$ ) radio waves which are backscattered from decametre-scale ionospheric electron density irregularities. In addition to backscattered power, the line-of-sight (1-o-s) Doppler velocity and Doppler spectral width of backscattered signals are recorded simultaneously at two similar but distinct frequencies (typically separated by a few tens of 


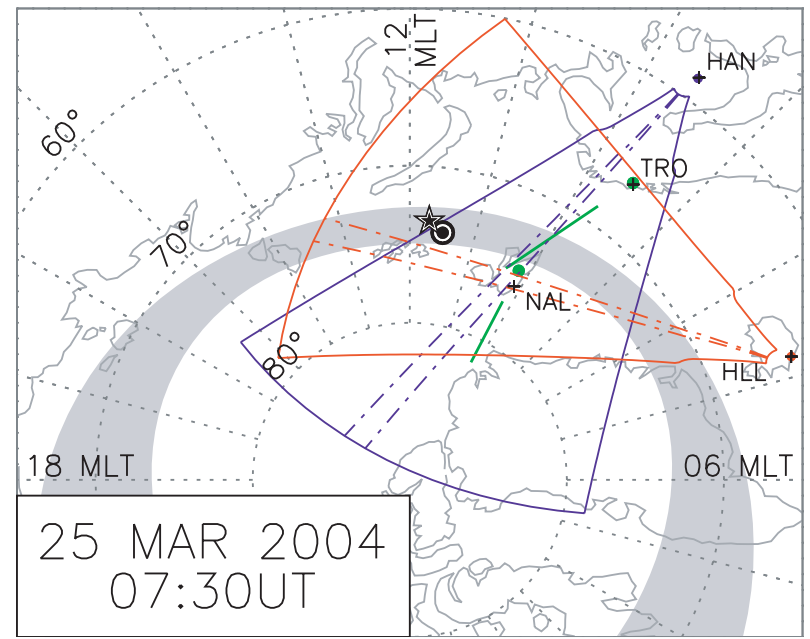

Fig. 2. A magnetic local time/magnetic latitude projection of the Northern Hemisphere at 07:30 UT on 25 March 2004. Concentric circles indicate parallels of constant magnetic latitude at $80^{\circ}, 70^{\circ}$ and $60^{\circ}$ magnetic latitude. The radial lines indicate hours of magnetic local time with noon located at the top of the figure. The statistical location of the auroral oval for appropriate magnetic activity is also indicated (after Feldstein and Starkov, 1967).The fields-ofview of the CUTLASS pair of SuperDARN radars are superimposed; the CUTLASS Finland radar in blue and the CUTLASS Iceland radar in red. Within these fields-of-view, the high time resolution beams beams employed in this study are indicated by dot-dashed lines. The poleward-looking low elevation beam of the ESR (between $150-500 \mathrm{~km}$ altitude) and the beam of the EISCAT Troms $\varnothing$ VHF radar (between $150-650 \mathrm{~km}$ altitude) are indicated by the solid green lines. Also shown are the magnetic footpoints of the TC1 and C1 spacecraft spacecraft (star-shaped and circular symbols, respectively) derived using the T96 magnetic field model parameterised appropriately for upstream solar wind conditions at 07:30 UT.

$\mathrm{kHz}$ ). Thus, operating in this "stereo" mode (Lester et al., 2004), each CUTLASS radar scans its full 16-beam field-ofview (f-o-v) at 1 min cadence while simultaneously sounding one beam at high $(3 \mathrm{~s})$ temporal resolution.

The EISCAT Svalbard radar (ESR) facility at Longyearbyen (Wannberg et al., 1997) consists of two separate colocated antennas. In this paper, we shall present $64 \mathrm{~s}$ resolution data from the steerable $32 \mathrm{~m}$ dish which operates at UHF frequencies $\sim 500 \mathrm{MHz}$. During the interval of interest, the antenna was directed northward at low elevation, with a geographic azimuth of $336^{\circ}$ and an elevation of $30^{\circ}$. As such, the ESR beam was pointing along the local magnetic meridian and almost aligned with the high temporal resolution beam of the CUTLASS Finland radar. Observations from the fixed, field-aligned $42 \mathrm{~m}$ ESR antenna, although operational, are not used in this paper. The location of the site on the Svalbard archipelago is shown by the green dot in Fig. 2 while the direction of the beam between altitudes $150-500 \mathrm{~km}$ is indicated by the green line. The EISCAT
VHF radar (Rishbeth and van Eyken, 1993, and references therein), located near Troms $\varnothing$ on the Scandinavian mainland, was also operating on this day. The beam of the VHF radar, operating at $\sim 224 \mathrm{MHz}$, was also directed northward at low elevation, with a geographic azimuth of $345^{\circ}$ and an elevation of $30^{\circ}$ (i.e. pointing toward Svalbard) and yielded measurements at $30 \mathrm{~s}$ resolution. The location of the radar and VHF beam between $150-650 \mathrm{~km}$ altitude are also shown in Fig. 2. Both radars used alternating code measurement techniques to provide profiles of electron density, electron and ion temperature, and ion velocity along the line-of-sight.

Magnetic field measurement are drawn from stations of the International Monitor for Geomagnetic Effects (IMAGE) magnetometer network (Lühr et al., 1998) and the UK SubAuroral Magnetometer Network (SAMNET: Yeoman et al., 1990). Data from the Hella (Iceland), Hankasalmi (Finland) and Borok (Russia) stations, provided by SAMNET, are recorded at $1 \mathrm{~s}$ resolution while data from the IMAGEoperated Troms $\emptyset$ (Norway) and Ny Ålesund (Svalbard) stations are recorded at $10 \mathrm{~s}$ resolution. The location of four of these stations (labelled with the three-letter identifiers HLL, HAN, TRO and NAL respectively) are indicated by crosses in Fig. 2. The other station, Borok (BOR), is located at $54.14^{\circ}$ magnetic latitude $\sim 10^{\circ}$ of longitude east of the Hankasalmi station and therefore does not appear in Fig. 2.

\section{Observations}

In this section, we shall introduce the various data exploited in this study. First we shall present the upstream observations of the solar wind and IMF, followed by in-situ observations of FTEs in the vicinity of the magnetopause. Finally, data recorded by ground-based experiments will be shown. Data first presented by Wild et al. (2005b) (hereafter referred to as Paper 1) will thus be augmented by new in-situ and remotelysensed measurements.

\subsection{Upstream solar wind observations}

Figure 3 presents an overview of solar wind and IMF observations made by the ACE spacecraft. As described in $\mathrm{Pa}-$ per 1 , these data have been lagged by $80 \mathrm{~min}$ such in order to take into account the propagation of solar wind/IMF structure from the spacecraft to the magnetopause. Throughout the 06:00-10:00 UT interval, the positive IMF $B_{Y}$ component dominated while the $B_{Z}$ component was generally small and positive, with only three brief southward excursions at $\sim 06: 15, \sim 08: 25$ and $\sim 08: 35$ UT (lagged time). This resulted in a generally duskward and northward oriented IMF clock angle. During the entire interval, the $B_{X}$ component was negative (i.e. Earthward pointing). The bulk solar wind speed was typically $\sim 350 \mathrm{~km} \mathrm{~s}^{-1}$ but fluctuating by approximately $\pm 10 \mathrm{~km} \mathrm{~s}^{-1}$ 

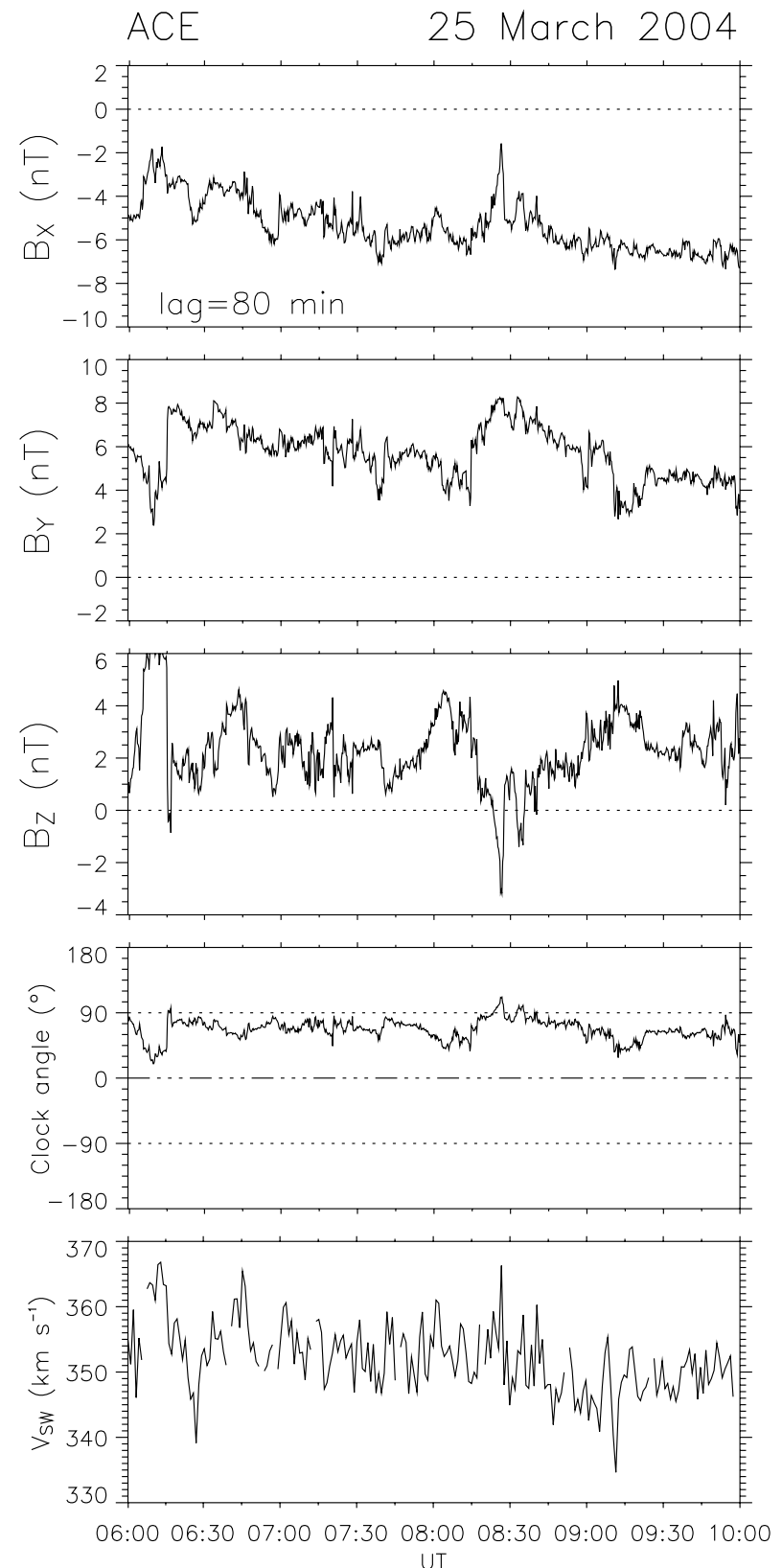

UT

Fig. 3. Solar wind and IMF measurements from the ACE spacecraft between 06:00-10:00 UT (lagged time). From top-to-bottom, the panels present the GSM $B_{X}, B_{Y}$ and $B_{Z}$ components of the interplanetary magnetic field, the IMF clock angle (defined as $\left.\arctan \left(B_{Y} / B_{Z}\right)\right)$ and the solar wind bulk speed.

\subsection{In-situ observations of FTEs}

Figure 4 presents the field and plasma measurements from the Double Star TC1 spacecraft during the interval 06:4507:30 UT. The magnetic field data are presented the boundary-normal coordinate systems introduced in Paper 1. In addition, variations in the magnetic field clock angle (defined as in Fig. 3) measured at both ACE and TC1 are also

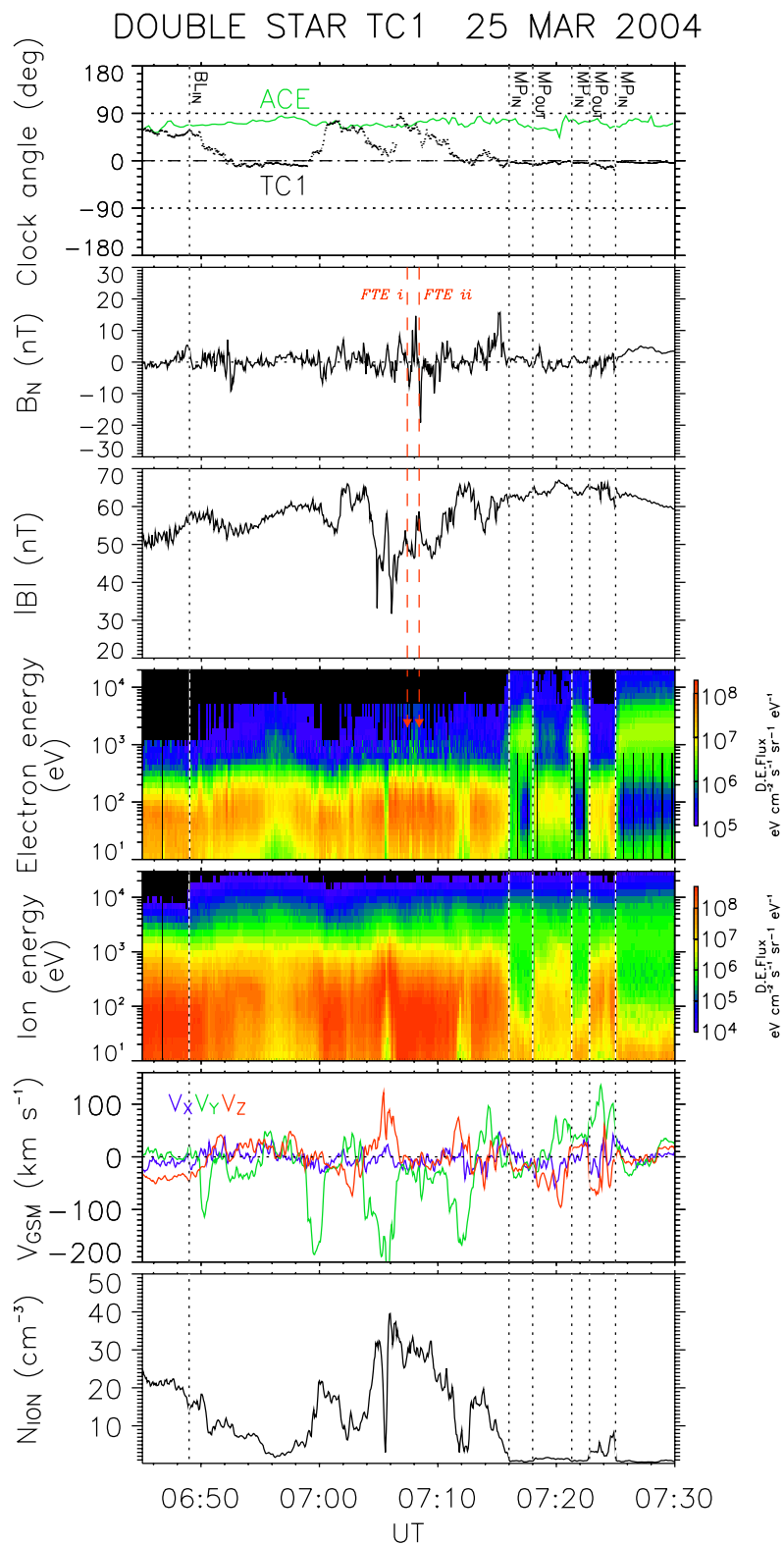

Fig. 4. Double Star field and plasma measurements between 06:4507:30. From top-to-bottom, the panels present; the magnetic field clock angle measured at TC1 (black) and ACE (green); the component of the magnetic field normal to the local magnetopause; the overall magnetic field strength; an energy-time spectrogram of electrons moving parallel to the local magnetic field; an ion energy-time spectrogram (all pitch angles); GSM $V_{X}$ (blue), $V_{Y}$ (green) and $V_{Z}$ (red) components of the ion bulk flow velocity; total ion density. Encounters with the boundary layer and magnetopause are indicated by dotted vertical line and labelled "BL" and "MP" respectively. The FTEs discussed in the text are indicated by dashed red lines.

shown. The presented plasma measurements comprise electron and ion energy-time spectrograms from the PEACE and CIS instruments respectively. In the case of the PEACE data, the spectrogram corresponds to electrons travelling parallel 
to the local field direction. For CIS, only data corresponding to all ion pitch angles were available. Ion velocity and density moments derived from CIS data are also shown.

At the beginning of the interval, the TC1 spacecraft was located in the magnetosheath. The IMF clock angle was very similar to that observed by the ACE spacecraft some $225 R_{E}$ upstream of the Earth when lagged as described above. Plasma measurements indicated a magnetosheath-like particle population characterised by a dense $\left(\sim 20\right.$ ions $\left.\mathrm{cm}^{-3}\right)$ but cool plasma (peak ion energy $<1 \mathrm{keV}$ ). Just prior to 06:50 UT, TC1 entered a boundary layer in which the magnetic field clock angle deviated from the upstream orientation and rotated toward the magnetospheric field direction $\left(\sim 0^{\circ}\right)$. Simultaneously, the observed ion density dropped by $\sim 50 \%$ while the upper-energy cutoff of the local electron and ion populations approximately doubled. At 06:50 UT, TC1 encountered a region of predominantly dawnward ion flow in excess of $100 \mathrm{~km} \mathrm{~s}^{-1}$ that lasted for $\sim 1 \mathrm{~min}$. Prior to the observation of this feature, the observed plasma flow speed was $\sim 50 \mathrm{~km} \mathrm{~s}^{-1}$ and directed predominantly southward and antisunward, as expected from TC1's location just south of the subsolar point. Based upon clock angle data only (as in Paper 1), the time of entry into the magnetosphere had been determined to be 06:50 UT. Taking into account the plasma data now available, we infer that the spacecraft actually entered a boundary layer at 06:50 UT and moved into the magnetosphere proper during the latter part of the interval.

While in the boundary layer, between $\sim 06: 50-07: 16 \mathrm{UT}$, the ion density observed at TC1 varied between 230 ions $\mathrm{cm}^{-3}$. Reductions in plasma density $\left(<5\right.$ ions $\left.\mathrm{cm}^{-3}\right)$ were accompanied by significant decreases in the flux of ions with energies $<0.5 \mathrm{keV}$ and an increase in the flux of $>2 \mathrm{keV}$ ions. These plasma density/energy features coincided with the largest deviations of the magnetic field clock angle from the upstream orientation $\left(75^{\circ}-90^{\circ}\right)$ toward the magnetospheric orientation $\left(\sim 0^{\circ}\right)$. We therefore interpret these variations as symptoms of the spacecraft's position within the boundary layer relative the to magnetopause which was, presumably, moving in response to the upstream solar wind and IMF conditions.

At 07:16 UT, TC1 entered a region in which the ion density was $<1$ ion $\mathrm{cm}^{-3}$, ion and electron energies extended up to $\sim 10 \mathrm{keV}$ and the local magnetic field was oriented in a northward direction. This transition from a cool/dense plasma to a hot/tenuous plasma marked TC1's entry into the magnetosphere. Over the next $10 \mathrm{~min}$, TC1 rapidly traversed the magnetopause four times (two outbound and two inbound crossing), entering the magnetosphere for the final time at 07:25 UT.

While in the boundary layer (06:59-07:16 UT), TC1 encountered a series of magnetic field perturbations. More specifically, numerous bipolar fluctuations in the component of the magnetic field normal to local magnetopause with peak-to-peak amplitude $\sim 10 \mathrm{nT}$ were observed. Examples include those at 06:52, 07:06, 07:07 and 07:08 UT. These are reminiscent of the classic bipolar FTE signatures first reported by Russell and Elphic (1978) and numerous authors since. However, due to the highly variable nature of the magnetic field in this boundary layer region, care must be taken in identifying possible FTE signature. As such, only bipolar signatures that are accompanied by local enhancements in the overall magnetic field strength and indications of magnetosheath/magnetosphere plasma mixing will be considered further. Two bipolar perturbations meet these criteria and are indicated by the dashed red lines in Fig. 4 (labelled "FTE $i$ " ( 07:07 UT) and "FTE ii" ( 07:08 UT) respectively). In each case, the overall magnetic field strength exhibits a clear local maximum as the bipolar $B_{N}$ component perturbation goes through $0 \mathrm{nT}$ from positive to negative values - indicating that these are "normal" polarity perturbations (Russell and Elphic, 1978, 1979) accompanied by low fluxes of magnetospheric electrons in the $0.5-2 \mathrm{keV}$ range.

Figure 5 presents equivalent field and plasma data recorded by the Cluster 1 (C1) spacecraft during the interval 07:45-08:45 UT (i.e. shortly after the interval presented in Fig. 4). At this time, the Cluster spacecraft were situated at approximately the same magnetic local time as the Double Star satellite, but at much higher latitude, as shown in Fig. 1. At 07:45 UT, the start of the interval shown in Fig. 5, Cluster 1 was located within the magnetosphere. The northward and duskward pointing magnetic field $\left(\sim 20^{\circ}\right.$ clock angle) is consistent with the spacecraft's location in the high-latitude, pre-noon sector magnetosphere. CIS and PEACE plasma measurements indicate that the spacecraft was surrounded by hot, tenuous magnetospheric plasma. Just prior to 07:50 UT, C1 entered a boundary layer in which the ion density increased dramatically, as did fluxes of lower energy $(\sim 100 \mathrm{eV})$ electrons and ions. Over the following $12 \mathrm{~min}$, the spacecraft observed bursts of high electron and ion fluxes in the $<0.5 \mathrm{keV}$ and $20 \mathrm{eV}-2 \mathrm{keV}$ ranges respectively accompanied by up to forty-fold increases in the ion density. The ion flow velocity, which prior to entering the boundary layer had been duskward and southward with speed $\sim 50 \mathrm{~km} \mathrm{~s}^{-1}$, increased with peak velocities in excess of $100 \mathrm{~km} \mathrm{~s}^{-1}$ and was highly variable (in both speed and direction). The magnetopause boundary layer was neither uniform or stationary. During traversal of the layer (or layers), several distinct plasma regions were encountered, notably regions characterised by the magnetospheric plasma only (e.g., $\sim 07: 56: 30$ UT), regions characterised by the magnetosheath plasma only (e.g. $\sim 07: 52$ and $\sim 07: 58$ UT) and regions with mixed magnetosheath and magnetospheric plasma, (e.g. 07:57:00 UT).

At about 08:01 UT, Cluster 1 was engulfed by dense $\left(\sim 25\right.$ ions $\mathrm{cm}^{-3}$ ) cool plasma as it entered the magnetosheath proper. After this time, the magnetic field clock angle orientation was generally in good agreement with the (lagged) upstream observations and the ion flow directed predominantly antisunward and northward. We note that the PEACE instrument switch off at 08:30 UT and the CIS experiment was 
inactive for 2 brief intervals (centred on 08:56 and 08:31 UT) resulting in short data gaps. After 08:32 UT, the CIS instrument operated at a reduced temporal resolution of $24 \mathrm{~s}$ (compared to $4 \mathrm{~s}$ resolution before this time).

Turning now to the Cluster $1 B_{N}$ component magnetic field data, several bipolar fluctuations were observed during the interval presented in Fig. 5. As was the case with TC1 data, we shall concentrate our attention on bipolar $B_{N}$ perturbations that are accompanied by clear enhancement in the overall magnetic field strength and evidence of magnetospheric/magnetosheath plasma mixing. As such, we have identified six events for further study, namely those at 08:20, 08:24, 08:27, 08:29, 08:32, and 08:35 UT (labelled "FTE $a-f$ " respectively). While FTEs $e$ and $f$ fall outside the PEACE data coverage, there is some evidence in the lower resolution CIS data of plasma mixing. These exceptionally clear magnetic signatures are therefore included in the subsequent analysis. Bipolar $B_{N}$ component perturbations were also observed in the regions dominated by magnetosheath plasma (e.g. $\sim 07: 52$ and $\sim 07: 58$ UT) as the spacecraft passed through the boundary layer. Indeed, in Paper 1 these events were identified as likely FTEs (based on magnetic field data alone). However, given the provision of plasma measurements which place these FTE candidates within the complex magnetopause boundary layer, it is difficult to uphold this inference with reasonable confidence. As such, these events shall not be considered further below.

\subsection{Ionospheric observations}

Figure 6 presents backscattered power, 1-o-s Doppler velocity and Doppler spectral widths measured by the CUTLASS Finland SuperDARN radar during the period 05:0009:00 UT on 25 March 2005. More specifically, these data were recorded along beam 9 , the single beam sounded by the high time resolution ( $3 \mathrm{~s}$ ) channel of the Finland radar (as indicated in Fig. 2). The measured parameters associated with ionospheric echoes are colour-coded according to the colour scale to the right of each panel. As shown in Fig. 2, this beam of the Finland radar is approximately aligned with the magnetic meridian. Thus, positive (negative) velocity measurements correspond to flow toward (away) from the radar in an roughly equatorward (poleward) direction. Backscattered signals that have been identified as ground scatter $\left(V_{1-\mathrm{o}-\mathrm{s}}<50 \mathrm{~m} \mathrm{~s}^{-1}\right.$ and spectral width $\left.<100 \mathrm{~m} \mathrm{~s}^{-1}\right)$ are shaded grey in the line-of-sight velocity panel.

At 05:00 UT, the Finland radar observed a region of ionospheric backscatter extending $\sim 4^{\circ}$ poleward of $79^{\circ}$ magnetic latitude. This ionospheric scatter was superimposed upon an area of ground-scatter echoes spanning the entire latitudinal range presented in the figure. However, over the course of the following three hours, the latitudinal extent of the band of ionospheric backscatter gradually decreased until, by 08:00 UT, it had almost entirely disappeared. This is clearest in the centre panel of Fig. 6 which presents the 1-o-s iono-

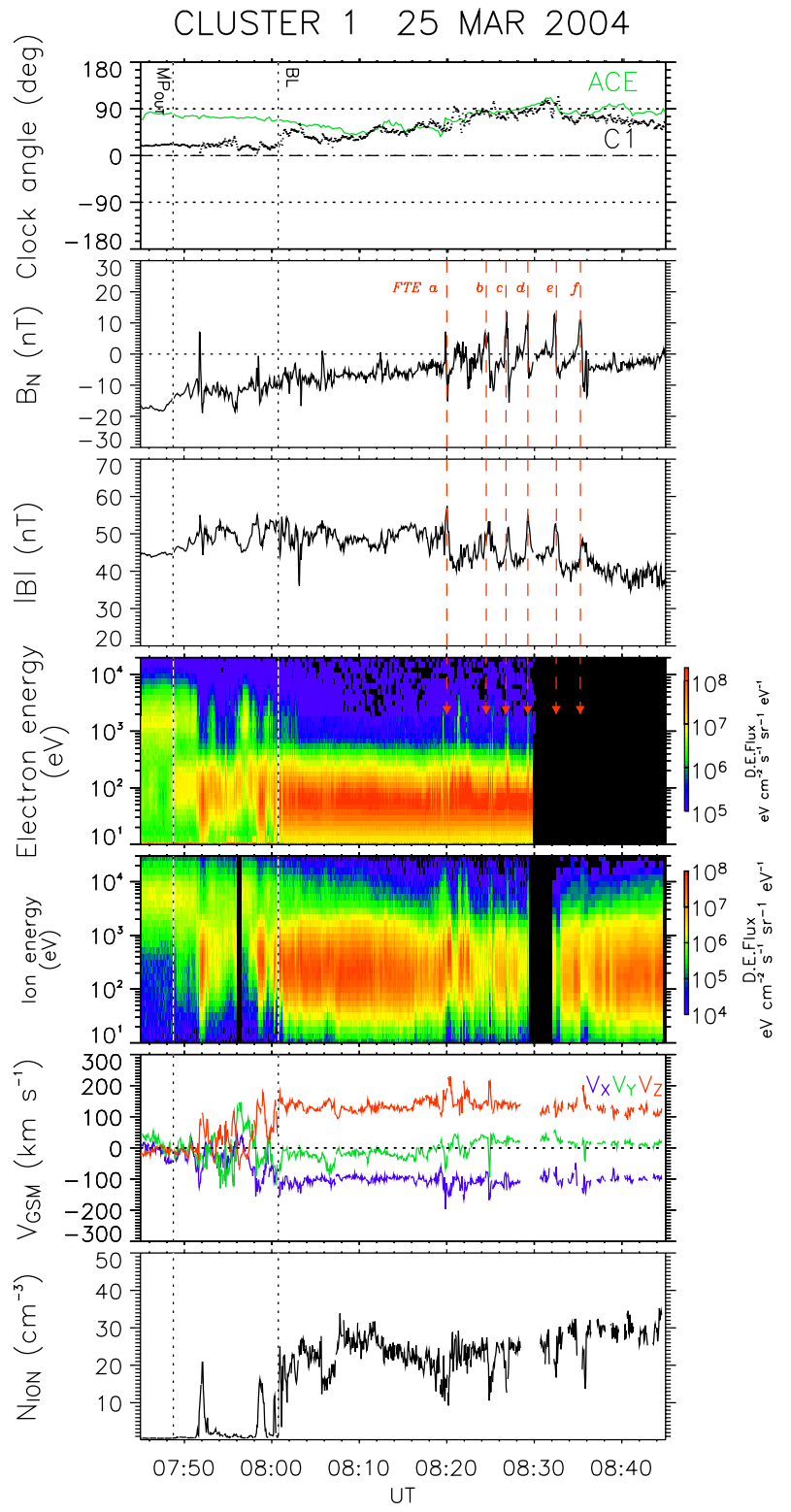

Fig. 5. Field and plasma measurements from the Cluster 1 spacecraft between 07:45-08:45. From top-to-bottom, the panels present; the magnetic field clock angle measured at TC1 (black) and ACE (green); the component of the magnetic field normal to the local magnetopause; the overall magnetic field strength; an energy-time spectrogram of electrons moving parallel to the local magnetic field; an energy-time spectrogram of ions moving parallel to the local magnetic field measured by the CIS Hot Ion Analyser (HIA); GSM $V_{X}$ (blue), $V_{Y}$ (green) and $V_{Z}$ (red) components of the ion bulk flow velocity (also from CIS HIA); total ion density. Encounters with the boundary layer and magnetopause are indicated by dotted vertical line and labelled "BL" and "MP" respectively. The FTEs discussed in the text are indicated by dashed red lines.

spheric velocities measured by the radar and clearly differentiates between the ionospheric and ground scatter regions. 


\section{CUTLASS Finland Beam 9}
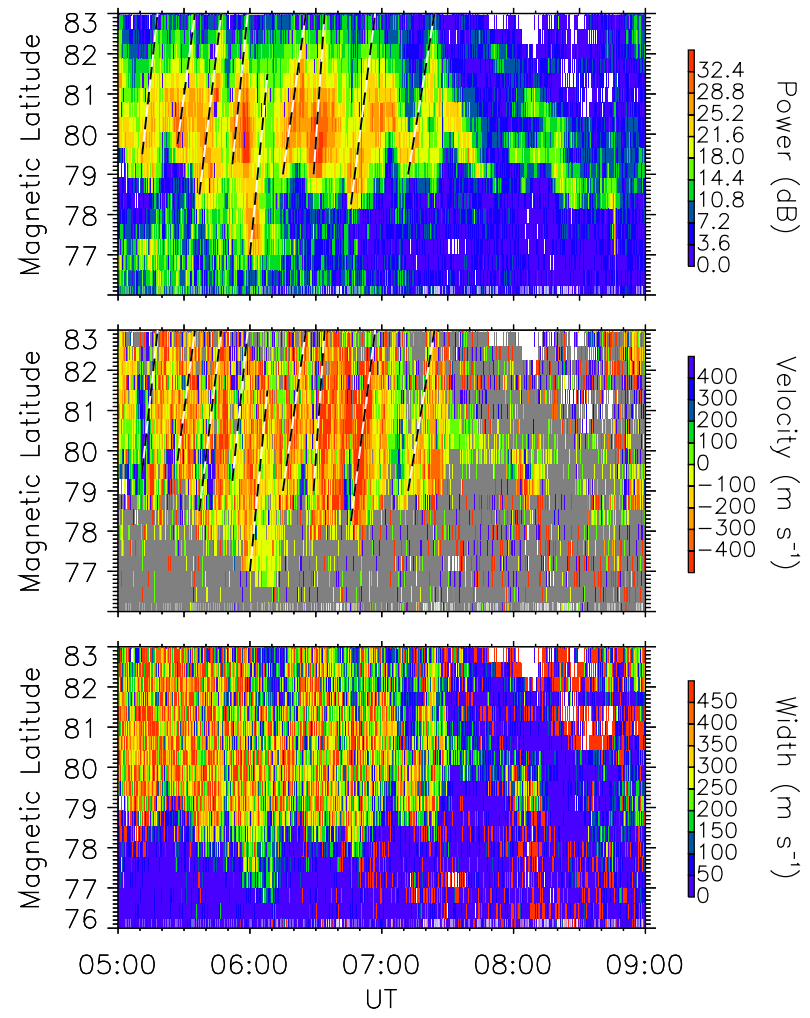

Fig. 6. Backscattered power, Doppler line-of-sight velocity and Doppler spectral width measurements from Beam 9 of the CUTLASS Finland SuperDARN radar. Data are presented as a function of magnetic latitude and universal time with each parameter colour-coded according to the scales shown on the right hand side. Transient features described in the text are highlighted by black and white dashed lines.

Note that the ionospheric echoes correspond to regions of high backscattered power (top panel) and regions of apparently very large spectral width.

Within the region of ionospheric scatter observed by the Finland radar, poleward moving structures were observed throughout the interval. These are clearly visible as areas of high backscattered power moving away from the radar toward higher latitudes. Dashed lines have been overlaid on the backscattered power and velocity panels of Fig. 6 to emphasise these features. The poleward speed of these structures, computed by tracking the motion of each high power echo features over a few-minute interval and corresponding to the slopes of the dashed lines, varies between $0.8-1.5 \mathrm{~km} \mathrm{~s}^{-1}$. In general these poleward-moving regions are associated with a relatively large 1-o-s velocity component $\left(>500 \mathrm{~m} \mathrm{~s}^{-1}\right) \mathrm{di}-$ rected away from the radar. However, strong equatorward flows (toward the radar) are also observed, although these are generally short-lived and occur in the lower latitude portion of the ionospheric backscatter.
CUTLASS Iceland Beam 5
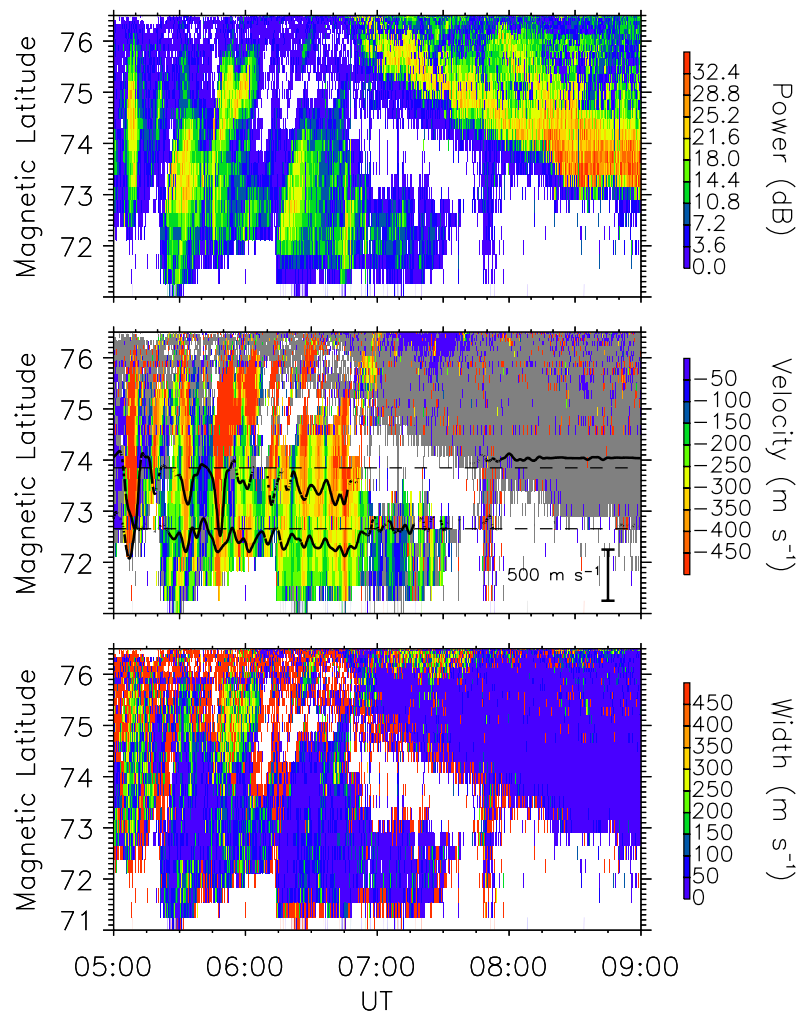

Fig. 7. Backscattered power, Doppler line-of-sight velocity and Doppler spectral width measurements from Beam 5 of the CUTLASS Iceland SuperDARN radar. Data are presented as a function of magnetic latitude and universal time with each parameter colourcoded according to the scales shown on the right hand side. Lineof-sight velocity time-series from range gates 23 and 28 are overlaid at the appropriate latitudes.

The poleward moving structures are very similar to the "pulsed ionospheric flows" (PIFs) reported by Pinnock et al. (1995) and Provan et al. (1998) - now widely accepted as the ionospheric signatures of FTEs. They correspond to regions of high speed ionospheric plasma flow at the footprint of newly-reconnected magnetic flux tubes as they are dragged away from the reconnection site by the combined action of solar wind flow and magnetic tension. In this case, the PIFs are observed in the region westward (dawnward) and poleward of the footprint of the TC1 and $\mathrm{C} 1$ satellite.

Figure 7 shows the corresponding measurements along the high time resolution beam (beam 5) of the CUTLASS Iceland SuperDARN radar. This beam points in a more zonal direction than the equivalent high time resolution beam of the Finland radar. Thus, whereas velocity measurements toward/away from the Finland radar roughly correspond to equatorward/poleward motion, equivalent measurements made by the Iceland radar contain a significant east-west component. During the interval presented ionospheric flows 
directed away from the radar, i.e. poleward and eastward, were observed. As such, the velocity colour scale differs from that employed in Fig. 6.

In contrast to the measurements from the Finland radar, the backscattered signals received by the Iceland radar originated from much lower latitudes - typically equatorward of $76^{\circ}$ magnetic latitude. Within this region of backscatter, the 1-o-s velocity fluctuated between approximately +200 and $-700 \mathrm{~m} \mathrm{~s}^{-1}$ with a periodicity of $\sim 10 \mathrm{~min}$. In order to emphasise these fluctuations, 1-o-s velocity time-series have been extracted from range gates 23 and 28 are overlaid on the line-of-sight velocity panel of Fig. 7. In each case, a dashed line indicates the latitude of the relevant range gate and the $0 \mathrm{~m} \mathrm{~s}^{-1}$ level. In keeping with the underlying plot, positive/poleward velocities are above the dashed line while negative/equatorward velocities are below. The deflection of the trace corresponding to a $500 \mathrm{~m} \mathrm{~s}^{-1}$ velocity is also shown. These measurements indicate a pulsing of the ionospheric flow in the poleward and eastward direction with a periodicity in the ultra-low frequency (ULF) range.

The CUTLASS radar measurements can be placed into context by considering the large scale ionospheric convection pattern that characterised the interval. Figure 8 shows the ionospheric convection pattern in Northern Hemisphere derived from ionospheric plasma velocity measurements using the "map potential" technique of Ruohoniemi and Baker (1998). This technique yields large-scale global convection maps from the 1-o-s velocity measurements from 9 Northern Hemisphere SuperDARN radars, via mathematical fitting of the data to an expansion of the electrostatic potential in spherical harmonics. Firstly, the 1-o-s data are filtered and then mapped onto a polar grid. These "gridded" measurements are then used to determine a solution for the electrostatic potential distribution that is most consistent with the available measurements. The electric potentials of the solution then represent the plasma streamlines of the modelled convection pattern. As backscatter targets (and therefore 1-o$\mathrm{s}$ velocity measurements) are not always available, information from the statistical model of Ruohoniemi and Greenwald (1996), parameterised by IMF conditions, is used to stabilise the solution where no measurements are made. In this case, the convection maps have been produced from ionospheric flow measurements averaged over $10 \mathrm{~min}$. This temporal averaging is necessary in this case since there were generally insufficient l-o-s data in each individual radar scan $(\sim 1 \mathrm{~min})$ to satisfactorily constrain the solution for the electrostatic potential.

Figure 8 presents the ionospheric convection pattern at 07:10, 07:30 and 08:30 UT overlaid on the CUTLASS radar fields-of-view (as presented in Fig. 2). These times have been chosen as they correspond to the period during which the TC1 and Cluster spacecraft observed the field and particle signatures of FTEs in the vicinity of the low and high latitude dayside magnetopause, respectively. The solid (dashed) black lines represent the negative (positive) equipotential
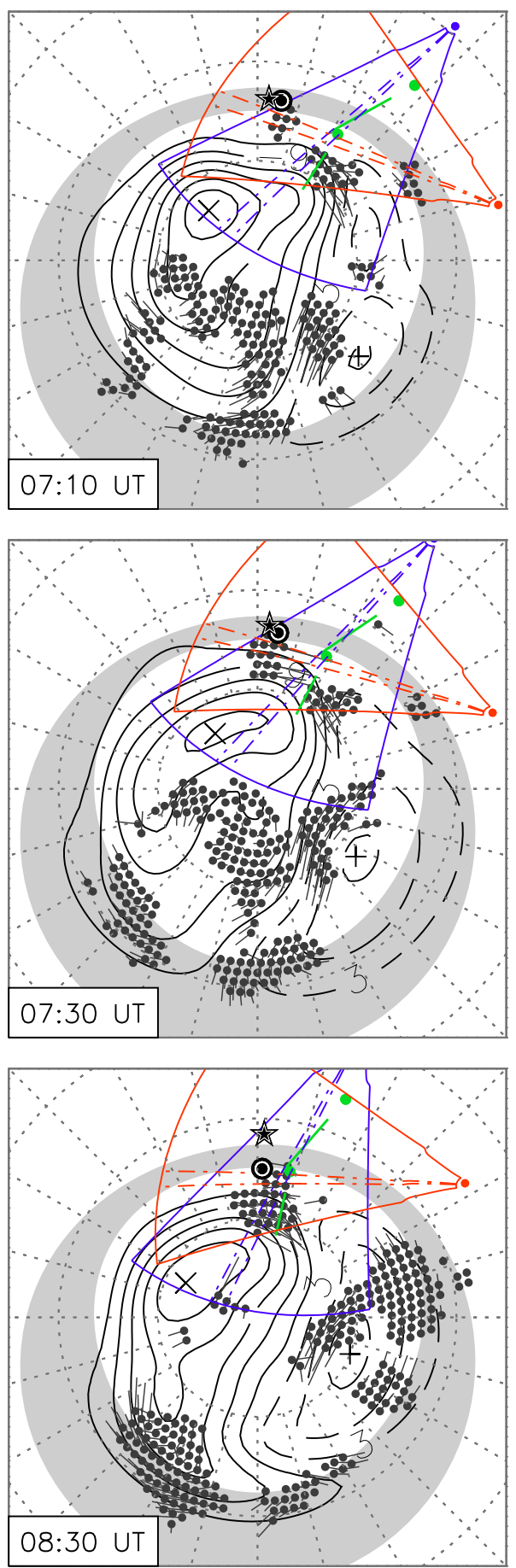

Fig. 8. Estimates of the Northern Hemisphere ionospheric convection pattern derived from SuperDARN observations of ionospheric flow, as described in the text. Also shown are the fields-of-view of the CUTLASS Finland and Iceland SuperDARN radars, the beams of the EISCAT VHF and ESR radars, and the footprints of the Double Star and Cluster spacecraft at the indicated time (same format as Fig. 2). 

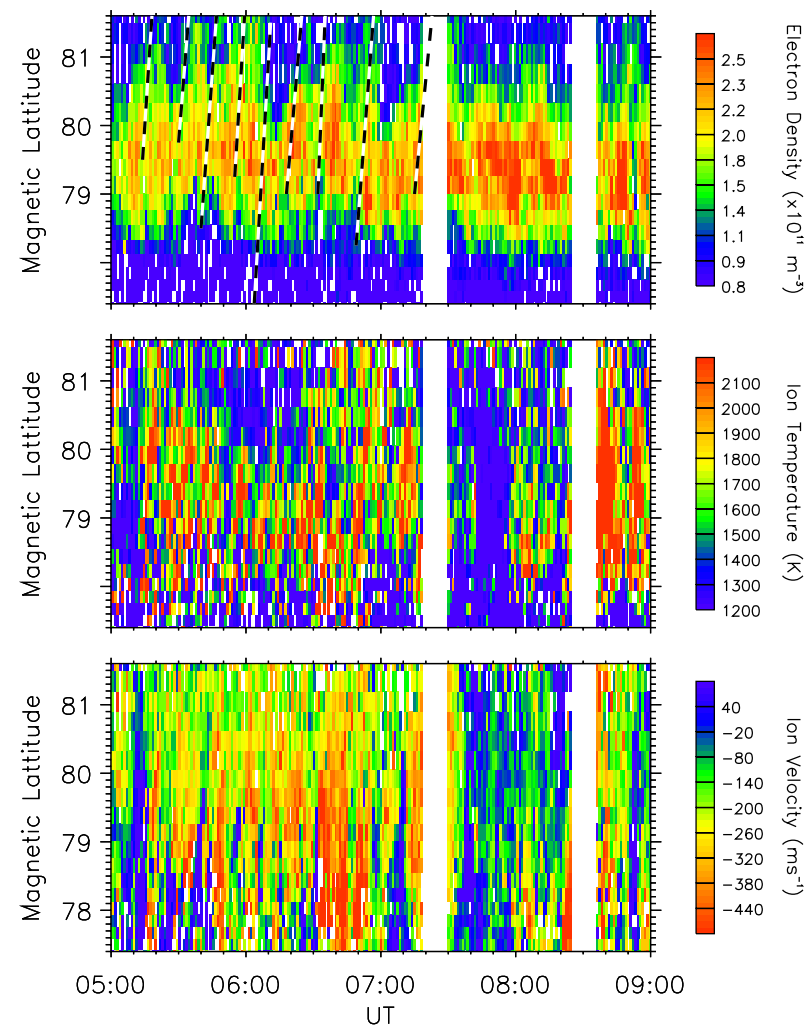

Fig. 9. Electron density, ion temperature and ion line-of-sight velocity measurements from low elevation northward pointing beam of the EISCAT Svalbard radar. Data are presented as a function of magnetic latitude and universal time with each parameter colourcoded according to the scales shown on the right hand side. Transient features described in the text are highlighted by black and white dashed lines.

contours, and therefore the ionospheric plasma flow streamlines, determined from the map potential algorithm. The dark grey dots indicate locations where radar 1-o-s velocity data are available (most of them measured by SuperDARN radars whose fields-of-view are not included in the figure). The flow vectors drawn from these dots, sometimes referred to as "true vectors", are calculated by combining the measured l-o-s velocity and the component of the convection flow (from the fitted solution) that is orthogonal to the 1-o-s direction (i.e. the radar beam) at each location. As in Fig. 2, the magnetic footprints of the TC1 and $\mathrm{C} 1$ spacecraft are also indicated for comparison.

Throughout the interval discussed in this paper, the global ionospheric convection pattern was dominated by the dusk convection cell, as expected for the prevailing IMF $B_{Y}$ positive conditions (Cowley and Lockwood, 1992). The PIFs presented in Fig. 6 are located within the $77-83^{\circ}$ region of the CUTLASS Finland radar beam indicated by the dotdashed lines within the blue field-of-view in Fig. 8. Based upon the 10-min averaged convection maps, this region corresponds to the "throat" of the ionospheric flow pattern, dawnward of the location of the TC1 and $\mathrm{C} 1$ footprints. Thus, the PIFs presented in Fig. 6 are consistent with the expected motion of poleward and dawnward moving ionospheric plasma associated with the newly-opened flux tubes produced by the FTEs observed at the Cluster and Double Star spacecraft.

Note that within the Finland radar's high time resolution beam, the ionospheric flow direction is predominantly directed across the beam, rather than along the 1-o-s direction. As such, relatively small reorientations in flow direction will result in a switch between 1-o-s flow toward/away from the radar. With this in mind, we interpret the short bursts of flow directed towards the radar presented in Fig. 6 as short-lived, spatially localised distortions of the average convection patterns presented in Fig. 8 resulting from the appendage of regions of newly-opened magnetic flux to the polar cap following a burst of dayside reconnection (e.g. Cowley and Lockwood, 1992). An examination of the 1-o-s velocities measured along beam 6 of the Finland radar (not shown) supports this interpretation. Beam 6 points into the throat of the ionospheric convection pattern shown in Fig. 8 such that plasma flow streamlines have a substantial component parallel to the 1-o-s direction. Although PIFs were observed in this beam, with structures moving away from the radar at speeds comparable to those discussed above, short-lived bursts of flow with a l-o-s component towards the radar were not recorded since small changes in the ionospheric flow pattern did not result in a directional switch of the l-o-s velocity component.

Figure 9 shows the simultaneous measurement of ionospheric electron density, ion temperature and ion velocity recorded by the EISCAT Svalbard radar. Although spanning a similar latitudinal range as the data presented in Fig. 6, the ESR's low elevation beam was not exactly aligned with beam 9 of the CUTLASS radar. At the $80^{\circ}$ magnetic latitude parallel, the CUTLASS and ESR beams are separated by around $60 \mathrm{~km}$ ( $3^{\circ}$ longitude), increasing to around $85 \mathrm{~km}$ ( $5^{\circ}$ longitude) at $82^{\circ}$ magnetic latitude. Nevertheless, the ESR data reveals a highly structured ionosphere in the throat of the ionospheric convection pattern with poleward moving structures very similar to those observed by the CUTLASS Finland radar. Like the CUTLASS radar, the ESR observed almost exclusively poleward plasma flow throughout the interval presented. Between 05:30-07:03 UT several high-speed PIFs were observed and were associated with poleward moving electron density enhancements. These correspond well with the PIFs observed by the CUTLASS Finland radar. Indeed, if the dashed lines from Fig. 6 are overlaid onto the top panel of Fig. 9 and shifted in time for $3 \mathrm{~min}$ in order to allow for a few-minute zonal propagation delay between the CUTLASS and ESR radar beams (equating to a zonal propagation speed of $\sim 0.5 \mathrm{~km} \mathrm{~s}^{-1}$ ), then this excellent agreement is apparent. These data support the interpretation above that the PIFs are the signature of magnetic reconnection (i.e. FTEs), the poleward moving regions of enhanced electron density corresponding to the ionospheric footprint of 
newly-reconnected flux tubes down which plasma originating the magnetosheath is precipitating into the ionosphere. These regions of high-speed $\left(>500 \mathrm{~m} \mathrm{~s}^{-1}\right)$ poleward plasma flow are also associated with region of enhanced ion temperature due to the relative velocity between the ions and the neutral atmosphere enhancing the temperature of the Fregion ion population via ion-frictional heating (e.g. Davies et al., 1997, 1999).

As an aside, we note that after $\sim 07: 30$ UT the 1-o-s ion velocity measured by the ESR across the latitude range presented in Fig. 9 dropped dramatically. The simultaneous drop in the ion temperature suggests that this was a genuine decrease in the ionospheric flow speed rather than a redirection of the flow orthogonal to the radar beam since high speed flow across the beam (i.e. with little or no 1o-s component) would still result in ion-frictional heating and elevated ion temperatures. By $\sim 08: 30 \mathrm{UT}$, about the time that Cluster observed FTEs in the high-latitude magnetosheath, high speed poleward directed flows were observed once again. Simultaneously, electron density structures were observed drifting towards and away from the radar at $\sim 200 \mathrm{~m} \mathrm{~s}^{-1}$. As indicated in Fig. 8, at 08:30 UT the ESR beam pointed into the anti-sunward flow region of the dusk convection cell. We therefore interpret the ESR observation of PIFs after $\sim 08: 00$ UT as further signatures of pulsed reconnection. The motion of the enhanced electron density features was most likely due to the meridional movement of the dawn-dusk ionospheric flow region across the pre-noon sector in response to the changes in the polar cap size resulting from ongoing dayside reconnection. There is some evidence of similar equatorward moving structures in backscattered power recorded by the Finland radar after 07:30 UT (Fig. 6). However, these structures are generally associated with very low 1-o-s Doppler velocity and classified as ground scatter and there is insufficient ionospheric backscatter to make a detailed comparison with the ESR observations at this time.

Figure 10 shows the simultaneous measurements of electron density, ion temperature and ion velocity over the 69$75^{\circ}$ range made by the EISCAT VHF radar situated in Troms $\varnothing$. As shown in Fig. 8, the VHF beam is oriented slightly eastward of a meridional pointing direction, therefore the generally negative l-o-s velocities observed (i.e. flow away from the radar) correspond to poleward and eastward directed flows. Like the CUTLASS Iceland radar, these measurements come from the region equatorward of the PIFs observed by the ESR and the CUTLASS Finland radars. Furthermore, like the Iceland radar, the EISCAT VHF system observed fluctuations in the ionospheric flow velocity in the ULF frequency range. The velocity fluctuations can clearly be seen in the time-series of 1-o-s velocity overlaid on the ion velocity panel. In this case, fluctuations of $\sim 5$ min period are superimposed on a longer period ( $\sim 40 \mathrm{~min})$ and there is evidence of poleward phase propagation of the shorter period wave signatures. In contrast to the ESR observations, made at an almost identical local time but at higher latitudes, there
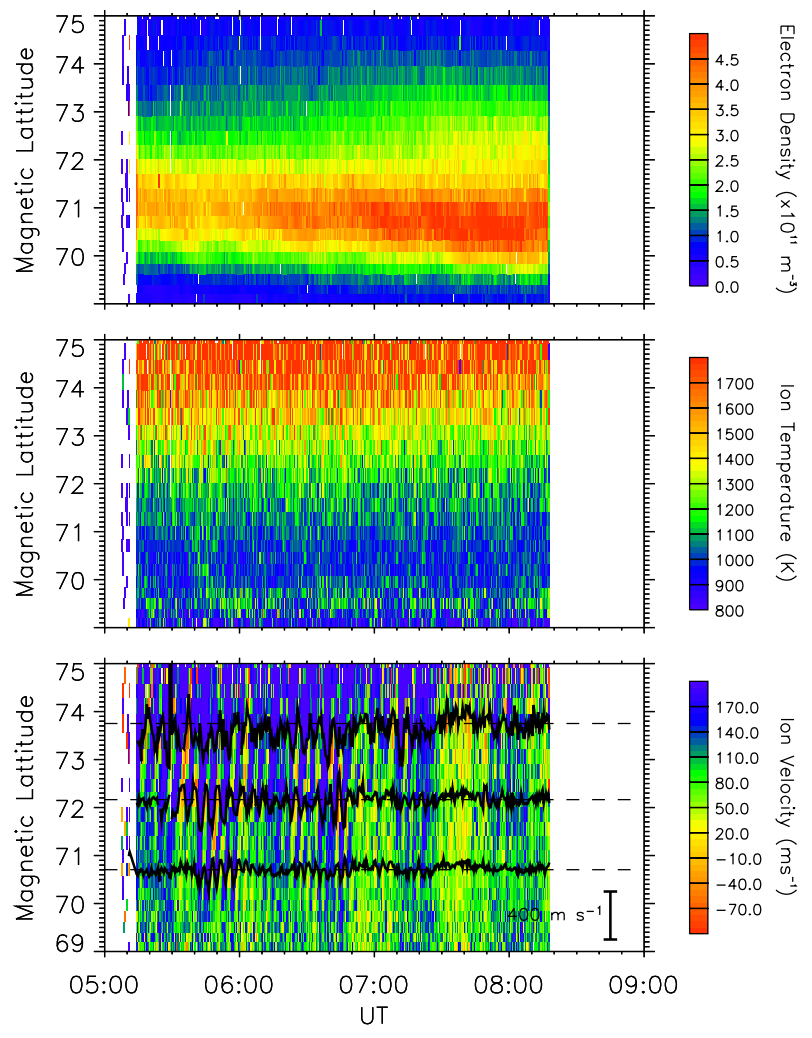

Fig. 10. Electron density, ion temperature and ion line-of-sight velocity measurements from low elevation northward pointing beam of the EISCAT VHF radar located in Troms $\varnothing$. Data are presented as a function of magnetic latitude and universal time with each parameter colour-coded according to the scales shown on the right hand side. Line-of-sight velocity time-series extracted at $70.7^{\circ}, 72.2^{\circ}$ and $73.8^{\circ}$ magnetic latitude are also overlaid.

are no indications of the dynamic structuring of the ionospheric electron density as seen further poleward.

Ground-based magnetometers also recorded ULF wave activity across a wide range of local times. Figure 11 presents time-series of fluctuation in the east-west component of the magnetic field measured at the Ny Ålesund (NAL), Troms $\emptyset$ (TRO), Hankasalmi (HAN), Hella (HLL) and Borok (BOR) magnetometer stations. These data have been bandpass filtered to show variations with periodicities between 120$3600 \mathrm{~s}$ and reveal a mixture of wave frequencies, dominated by $\sim 30$ min pulsations. We also note that the oscillations observed at NAL are of much greater amplitude than those at stations equatorward of Svalbard. These measurements reveal that the pulsations observed by the CUTLASS and EISCAT radars extend over $\sim 8^{\circ}$ of magnetic latitude and well over $3 \mathrm{~h}$ of MLT. 

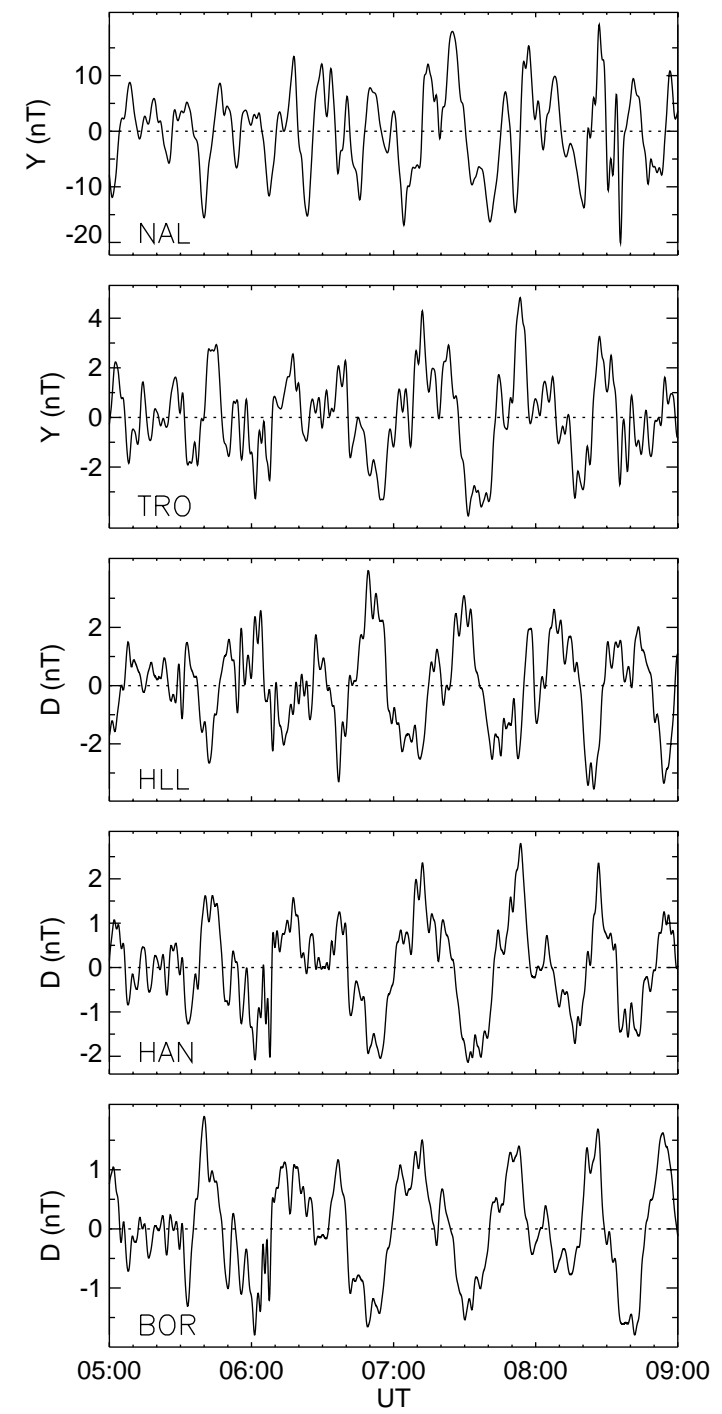

Fig. 11. East-west component magnetograms from stations of the SAMNET and IMAGE magnetometer networks, bandpass filtered to reveal oscillations with periods between $120-3600$ s.

\section{Discussion}

In this section we shall consider the ramifications of the space- and ground-based measurements presented above upon the coupling processes between the solar wind, magnetosphere and ionosphere under the interval of $B_{Y}$ dominated interplanetary magnetic field observed on 25 March 2004.

Firstly, we shall consider the location of the reconnection site(s) on the dayside magnetopause. In order to do this, we have employed a realistic model of open flux tube motion based on that of Cooling et al. (2001) (subsequently referred to as "the Cooling model"). This simple model, an evolution of the model of Cowley and Owen (1989), considers the draping and strength of the magnetosheath magnetic field, magnetosheath flow velocity, and density over the surface of a simple paraboloid magnetopause, based upon the models of Kobel and Flückiger (1994) and Spreiter et al. (1966). For given IMF and solar wind parameters, the model computes the instantaneous flux tube motion along the magnetopause at every point on the magnetopause surface due to the effects of stress balance in the reconnected flux tubes and magnetosheath flow, at the so-called de Hoffman-Teller velocity (de Hoffman and Teller, 1950). From this, the motion of open magnetic flux tubes threading the magnetopause can be traced, via iteration, over the surface of the magnetopause and into the magnetotail from any location on the surface of the magnetopause. As a by-product of the de HoffmanTeller velocity computation, the model also calculates the plasma velocity in the magnetopause boundary layer at all points on the surface of the magnetosphere (see Cowley and Owen, 1989, and references therein).

The first comparison between estimates of flux tube motion derived from the Cooling model and 3-D measurements of flux transfer events at the high-latitude magnetopause were presented by Wild et al. (2005a) and a similar analysis shall be employed here. In this modified implementation of the Cooling model, no steady-state reconnection test is applied. Instead, we shall monitor the subsequent motion of the newly-opened flux tubes (i.e. FTEs) away from a userdefined reconnection site. By doing this, we are able to compare the expected flux tube motion with the observed FTE signatures without making any assumptions regarding the necessary conditions/thresholds required for reconnection.

First, we shall investigate the inbound passage through the boundary layer and magnetopause made by the Double Star TC1 spacecraft at $\sim 07: 00$ UT. Figures $12 \mathrm{a}-\mathrm{c}$ present the estimates of boundary layer and flux tube motion at this time derived from the Cooling model. Each panel of Fig. 12 shows a view of the dayside magnetopause in the GSM $Y$ - Z plane as viewed from the Sun. The concentric dotted circles indicate the magnetopause in the GSM $Y$ - $Z$ plane at $X$ positions of $X=+5 R_{E}, 0 R_{E},-5 R_{E}$, and $-10 R_{E}$ while the cusps are represented by the diamond symbol. In this model, the cusps are positioned at the GSM locations [0.5 $R_{M P}$, $\left.0, \pm R_{M P}\right]$ where $R_{M P}$ is the radius of the model magnetopause at the subsolar point. In this case, $R_{M P}$ has been set to $10 R_{E}$, roughly the value predicted by the model of Shue et al. (1997) during this interval and consistent with the magnetopause location observed by the spacecraft. The prevailing IMF clock angle is indicated in the upper right-hand corner of each panel and the locations of the $\mathrm{C} 1$ and TC1 spacecraft in the GSM $Y$-Z plane are indicated by filled circle and star symbols, respectively.

In Figs. 12a and b, a reconnection X-line has been initiated at the sub-solar point and extended $5 R_{E}$ in the directions parallel and anti-parallel to the local magnetopause current (a function of the relative orientation of the magnetospheric and magnetosheath field at any given location). The coloured arrows show streamlines of boundary layer flow (Fig. 12a) and open flux tube motion (Fig. 12b) resulting from such 

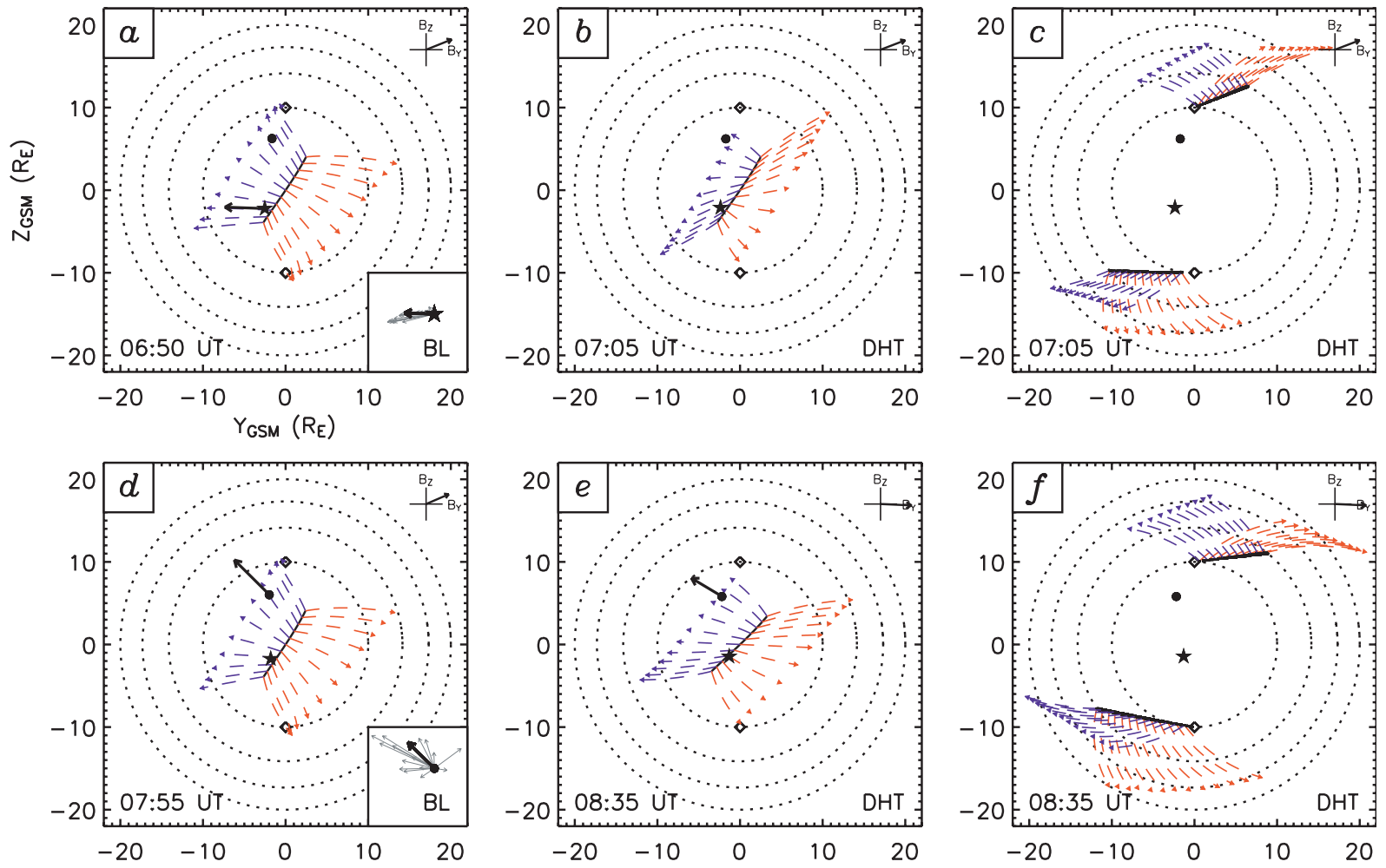

Fig. 12. Results of the Cooling model showing boundary layer plasma flow and open flux tube motion at the time of Double Star (a-c) and Cluster (e-f) observations. Each panel presents a view of the magnetopause as seen from the Sun. The IMF clock angle used for each computation is indicated in each panel and corresponds to the time shown. An X-line (solid black line) and flow streamlines showing either boundary layer motion (in panels marked "BL") or open flux tube motion at the de Hoffman-Teller velocity (in panels marked "DHT") are overlaid - dashed blue (red) vectors indicate motion corresponding to flux tube attached to the Northern (Southern) Hemisphere. The locations of the Cluster and Double Star satellite are shown by circular and star symbols, respectively, and experimentally-determined parameters overlaid as described in the text. In the panels presenting averaged observed boundary layer flow vectors (a and d), the individual measurements used in the averaging calculation are shown in the inset (bottom-right).

an X-line. Note the "BL" (Boundary Layer) and "DHT" (de Hoffman-Teller) labelling in the lower right-hand corner of each panel. Blue (red) dashed arrows indicate boundary layer flow and flux tube motion associated with flux tubes anchored in the Northern (Southern) Hemisphere ionosphere. As such, Fig. 12a shows the boundary layer flow from a subsolar X-line, tilted in the direction of the magnetopause current, for the IMF conditions observed at 06:50 UT (lagged time). This corresponds to the approximate time that TC1 encountered the magnetopause boundary layer as shown in Fig. 4. Figure $12 \mathrm{~b}$ shows the motion of open flux tubes from the equivalent X-line at 07:05 UT, the approximate time at which TC1 observed FTE signatures as it approached the magnetosphere. For comparison, Fig. 12c shows the open flux tube motion expected from a pair X-lines constrained to pass through locations where the magnetosheath and magnetospheric magnetic field are with $1^{\circ}$ of anti-parallel, using IMF parameters appropriate for 07:05 UT (as in Fig. 12b).

Thus, Fig. 12a indicates that a tilted $\mathrm{X}$-line passing through the sub-solar point would be located slightly south- ward of the TC1 spacecraft at 06:50 UT (the time at which $\mathrm{TC} 1$ entered the boundary layer). The boundary layer plasma flow at this location is expected to be predominantly westward (dawnward). The average boundary layer plasma flow direction measured by the CIS instrument on TC1 between 06:50-06:51 UT is indicated by a black arrow originating at the location of the spacecraft in Fig. 12a (for completeness the inset shows the individual measurements that make up the average boundary layer plasma flow vector). Clearly, there is excellent directional agreement between the observed and modelled boundary layer plasma flow at this location/time. These velocities are also summarised in Table 1. Closer examination reveals that the Cooling model is over-estimating the boundary layer flow speed, whereas the flow direction in the GSM $Y$-Z plane (roughly equivalent to the plane of the magnetopause at this location) is in good agreement with observations. However, the Sunward flowing plasma observed by TC1 in the boundary layer is unexpected and not described by the Cooling model. Figure $12 \mathrm{~b}$ demonstrates that newly-opened Northern Hemisphere flux tubes 


\begin{tabular}{ccccccccccrrr}
\hline & \multicolumn{4}{c}{ Boundary layer velocity $\left(\mathrm{km} \mathrm{s}^{-1}\right)$} & \multicolumn{4}{c}{ Flux tube velocity $\left(\mathrm{km} \mathrm{s}^{-1}\right)$} \\
& UT & & $V_{X}$ & $V_{Y}$ & $V_{Z}$ & & UT & & $V_{X}$ & $V_{Y}$ & $V_{Z}$ \\
\hline \multirow{2}{*}{ TC1 } & $06: 50$ & Obs & +28 & -78 & +1 & \multirow{2}{*}{$07: 05$} & Obs & - & - & - \\
& & Mod & -34 & -146 & +11 & & Mod & -30 & -139 & +11 \\
& & & Obs & -10 & -64 & +63 & & $08: 35$ & Obs & +9 & -55 & +33 \\
C1 & $07: 55$ & Mod & -103 & -90 & +141 & & Mod & -83 & -153 & +185 \\
& & & & & & & & & & & &
\end{tabular}

Table 1. A summary of the measured and modelled boundary layer and flux tube velocities presented in Fig. 12.

(colour-coded blue) from a tilted sub-solar X-line would be dragged over the TC1 spacecraft under the prevailing $B_{Y}$ dominated IMF conditions. While no measurement of flux tube velocity are available from the single TC1 spacecraft, the fact that flux tubes attached to the Northern (rather than Southern) Hemisphere are expected to pass over the TC1 spacecraft is consistent with the observation of normal (rather than reverse) polarity FTEs in the Double Star magnetometer data just after 07:05 UT (e.g. Rijnbeek et al., 1984). Figure 12c illustrates that under these IMF conditions, anti-parallel magnetic field configurations are to be found tailward and duskward (dawnward) of the northern (southern) cusp regions. In these regions of super-Alfvénic magnetosheath flow, reconnected flux tubes are dragged tailward, away from the location of the Double Star TC1 spacecraft. We therefore suggest that the FTE signatures observed by $\mathrm{TC} 1$ originated at a low-latitude $\mathrm{X}$-line, as shown in Fig. 12a/b, rather than a high latitude site, as shown in Fig. 12c. Of course, we cannot exclude the possibility that high latitude reconnection is occurring during this interval, but these processes are unlikely to account for the observed FTEs. Furthermore, we note that at the high-latitude sites (Fig. 12c), newly-opened flux tubes originating in both hemispheres are dragged tailward such that in the Northern Hemisphere, Southern Hemisphere field lines are dragged northward back across the reconnection site (and vice-versa). Under such conditions, steady reconnection would be impossible (Cowley and Owen, 1989) - any reconnection at these sites must be bursty in nature. For completeness, midlatitude reconnection sites on the dusk/dawn flanks were also investigated. As in the high-latitude case, super-Alfvénic magnetosheath flow carried such flux tubes tailward, away from the Double Star and Cluster spacecraft located in the noon sector.

Figures $12 \mathrm{~d}-\mathrm{f}$ show equivalent comparisons between observations made by the Cluster spacecraft and the Cooling model. Figure 12d shows the expected boundary layer flow streamlines at 07:55 UT, corresponding to the time at which $\mathrm{C} 1$ was embedded within the magnetopause boundary layer. Overlaid on these is an arrow indicating the plasma flow direction at $\mathrm{C} 1$ derived from CIS ion moments averaged between 07:55-07:56 UT (repeated in Table 1). Once again, we note that there is good agreement between the direction of the observed and estimated flow direction in the GSM $Y$-Z plane, although the flow speed has been overestimated by the Cooling model. A significant discrepancy in the $V_{X}$ component of the boundary layer plasma flow is observed in this case also. Given the multi-spacecraft measurements available at the location of Cluster, it is possible to estimate the velocity of FTE structures as they pass by the spacecraft based upon a timing analysis of the structure as it advects over each satellite (e.g. Dunlop and Woodward, 1998). Figure 12e presents the estimated motion of open flux tubes from an X-line passing through the sub-solar point under the almost purely dawnward IMF conditions as observed at 08:35 UT (lagged time). This corresponds to the time at which the final FTE was observed by Cluster ("FTE f' in Fig. 5). The estimated direction of the FTE observed by Cluster at this time - derived via multi-spacecraft timing analysis - is overlaid at the appropriate location of the $\mathrm{C} 1$ spacecraft (the corresponding velocity components are presented in Table 1). As with boundary layer flow comparison, there is very good agreement between the direction of motion in GSM Y-Z plane observed by Cluster and that predicted by the Cooling model. Again, the flow speed is overestimated by the model and there is poor agreement between the observed and modelled $V_{X}$ component (which at this location points roughly outward from the magnetopause). The velocity estimated from the multi-point Cluster data is based upon the assumption that the FTE can be approximated to a planar structure - the resulting velocity estimate will be directed orthogonally to the planer surface. If we interpret the bipolar $B_{N}$ signature of an FTE as a bulge on the surface of the magnetopause, it is not unreasonable to expect planarity over the Cluster tetrahedron $(\sim$ few $100 \mathrm{~km}$ scale size). However, as the bulge moves over the surface of the magnetopause, the normal to its leading edge will point outward from the magnetosphere. We therefore interpret the apparent outward motion of the structure that the Cluster satellites have measured as the motion of the FTE "bulge" past the tetrahedron as it moves over the surface of the magnetopause. This is not described by the Cooling model which simply indicates the motion of the newly-opened flux tube in the plane of the magnetopause. For completeness, we have again considered the location of regions of anti-parallel magnetosheath and magnetospheric field at 08:35 UT and the motion of open flux tubes that might be created by reconnection in these regions (Fig. 12f). As was the case at 07:05 UT, the $B_{Y}$ dominated IMF forces these regions to high latitudes, 
tailward of the cusps. We suggest that reconnection in these regions would (i) be unlikely to launch newly-opened flux tubes towards the Cluster spacecraft and (ii) is unlikely to be steady.

The ground-based data presented above support the interpretation that the FTE signatures are the consequence of a low-latitude X-line. For a low latitude reconnection site, we have shown that newly opened flux tubes would be expected to engulf both the $\mathrm{C} 1$ and $\mathrm{TC} 1$ spacecraft as they are dragged dawnward. The ionospheric footprint of such flux tubes would be expected to move dawnward and tailward as they were dragged into the polar cap under the effects of magnetic tension and magnetosheath flow - just as presented in Fig. 8 . The global ionospheric convection pattern derived from $\mathrm{Su}$ perDARN data indicates that plasma newly-reconnected flux tubes convect poleward and dawnward away from the footprint of the $\mathrm{C} 1 / \mathrm{TC} 1$ spacecraft which, given their proximity to the dayside magnetopause, are presumably located on the equatorward edge of the cusp. The high-speed flow associated with newly reconnected flux tubes as they crossed the cusp and moved into the polar cap gave rise to the PIFs observed by the CUTLASS Finland SuperDARN radar and the EISCAT Svalbard radar. Whereas both of these radars observed the high latitude ionosphere poleward of Svalbard (magnetic latitudes between $77^{\circ}-83^{\circ}$ ), the EISCAT VHF radar located on the Norwegian mainland measured no significant structuring of the ionospheric electron density in the region equatorward of Svalbard $\left(69^{\circ}-75^{\circ}\right.$ magnetic latitude). This is an indication of the lack of electron precipitation in this region. As such the region equatorward of Svalbard is inferred to correspond to closed magnetic field lines that do not map to the vicinity of the magnetopause. This is consistent with the ionospheric projection of the open/closed magnetic field line boundary (from which the PIFs originate) lying somewhere in the vicinity of Svalbard - certainly poleward of $75^{\circ}$ magnetic latitude. While neither CUTLASS radar observed PIFs after $\sim 07: 30$ UT, it is worth noting that this does not necessarily mean the absence of pulsed ionospheric flows. Instead, it suggests an absence of the decametre-scale ionospheric irregularities required to backscatter the HF signals that this measurement technique relies upon. The continued observation of PIF-like signatures by the ESR after 07:30 UT supports the inference that reconnection and pulsed ionospheric flows continued during the interval when the Cluster spacecraft were traversing the high latitude magnetopause (i.e. after 07:30 UT), but the CUTLASS radars were unable to detect the PIFs due to a lack of backscatter targets. Therefore we interpret the observations as compelling evidence of a tilted low latitude X-line during an interval of both northward and southward IMF strongly $B_{Y}$ dominated by a duskward component of the IMF, although these space- and ground-based measurements cannot rule out the simultaneous occurrence of high-latitude (anti-parallel) reconnection.

In addition to the pulsed ionospheric flows associated with reconnection at the magnetopause, ground-based radars and magnetometers observed wave-like perturbations in the ionospheric flow and magnetic field, respectively. These perturbation preceded, coincided with, and followed the two brief intervals when the Double Star and Cluster spacecraft were observing FTEs in the vicinity of the dayside magnetopause. Previous studies have linked pulsed magnetic reconnection, magnetospheric oscillations, field line resonance and periodic perturbations in the solar wind. For example, Prikryl et al. (1998) presented compressional MHD waves in the solar wind with a period $\sim 15 \mathrm{~min}$ that applied oscillating magnetic/electric fields and dynamic pressure on the dayside magnetopause. Convection flow bursts in the ionospheric footprint of the cusp were found to be closely correlated with low frequency oscillations of the IMF $B_{Z}$ and duskward electric field in the magnetosheath. Prikryl et al. (1998) concluded that the ULF waves in the solar wind modulated the magnetic reconnection at the dayside magnetopause into pulses. Rae et al. (2004) observed identical periodicity of the solar wind electric field, pulsed particle signatures in the cusp and the pulsed ionospheric flow signatures of magnetic reconnection. Rae and co-authors concluded that solar wind Alfvén waves modulated the dayside interaction between solar wind and magnetosphere producing periodic FTEs, pulsed cusp precipitation and poleward moving radar auroral forms (PMRAFs). Given the availability of radar and magnetometer data from the (pre-noon) Scandinavian sector during this interval, we shall briefly examine the periodic oscillations presented above and consider their significance to the reconnection signatures introduced above.

Figure 13 presents normalised Fourier transform spectra of the oscillations in the solar wind dawnward electric field measured at ACE (computed from $E_{Y}=-V_{X} \times B_{Z}$ ), the eastwest component of the magnetic field measured by the Ny Ålesund (NAL) and Hella (HLL) ground magnetometers, and the line-of-sight Doppler velocity measured at $\sim 72^{\circ}$ Mlat by the EISCAT VHF radar. In each case, time-series spanning the interval indicated have been high-pass filtered to leave periodicities less than $1 \mathrm{~h}$ (black trace) and $30 \mathrm{~min}$ (red trace). This corresponds to frequencies greater than $\sim 0.28 \mathrm{mHz}$ and $\sim 0.56 \mathrm{mHz}$ respectively. Note that in the case of the EISCAT 1-o-s data, the available time-series was $\sim 3 \mathrm{~h}$ in duration - considerably shorter than the other timeseries analysed. Therefore, only the $30 \mathrm{~min}$ high-pass filtered spectrum has been presented.

Clearly, between 06:00-09:00 UT on 25 March 2004, the dawn-dusk electric field in the lagged solar wind was dominated by fluctuations at a frequency of $0.55 \mathrm{mHz}(\sim 30 \mathrm{~min}$ periodicity) with a secondary local maximum at $0.35 \mathrm{mHz}$ ( $\sim 8 \mathrm{~min})$. On the ground, both the NAL and HLL spectra are dominated by a peak at $0.47 \mathrm{mHz}(\sim 35 \mathrm{~min})$. When periodicities greater than $1 \mathrm{~h}$ are filtered from the time series and the spectra re-analysed, the significance of the subsidiary peaks in the $0.7-1.2 \mathrm{mHz}$ range is emphasised - the higher frequency peaks in the NAL and HLL frequency spectrum exhibit some similarity to those in the dawn-dusk 

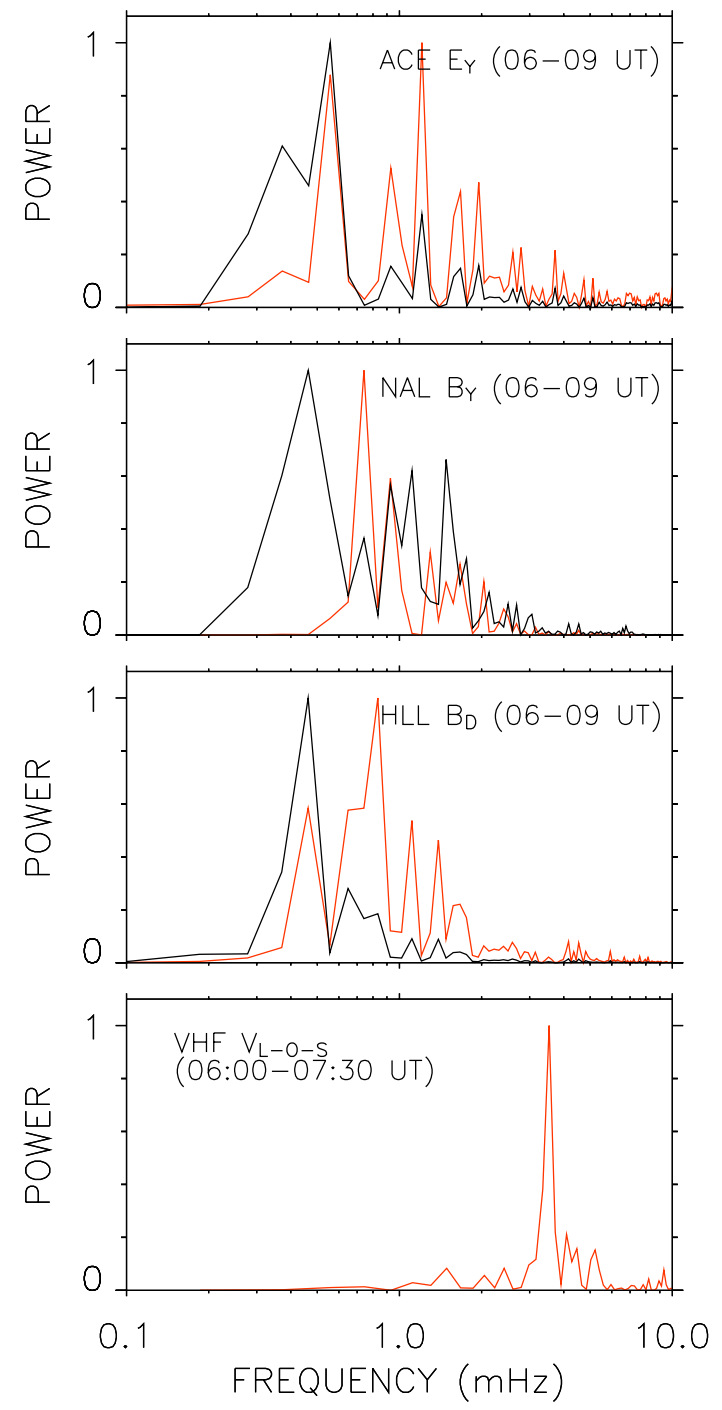

Fig. 13. Normalised frequency spectra showing oscillations with periodicity less that $3600 \mathrm{~s}$ (black trace) and $1800 \mathrm{~s}$ (red trace) in the dawn-dusk electric field measured at ACE, the east-west component of the magnetic field measured at the Ny ̊̊lesund (NAL) and Hella (HLL) ground magnetometers, and the 1-o-s ion velocity measured at $72^{\circ}$ magnetic latitude by the VHF EISCAT radar.

electric field spectrum. In contrast, fluctuations in the lineof-sight velocity measured along the approximately northward pointing beam of the EISCAT VHF radar were dominated by higher frequency oscillations. In this case, there is a sharp peak at $3.5 \mathrm{mHz}(\sim 5 \mathrm{~min})$ that dominates the spectrum. These are the very clear oscillations apparent in the time-series presented in Fig. 10 - the lower frequency "envelope" ( $\sim 0$ min period) having been suppressed by the highpass filter. Measurements from the DOppler Pulsation Experiment (DOPE: Wright et al., 1997; Yeoman et al., 2000) - not shown here - also indicated strong ionospheric wave propagation during this interval. The $5.73 \mathrm{MHz}$ propagation path between the DOPE transmitter and receiver (SkibotnTroms $\emptyset$ path) in northern Norway was disturbed by $\sim 30$ 40 min period oscillations that influenced the the refractive index and bulk motion of ionospheric plasma along path throughout the interval of interest.

The data presented above reveal that the dayside magnetosphere and ionosphere are alive with ULF wave activity during the interval in which magnetic reconnection was observed to occur. The order of magnitude increase in wave amplitude observed at NAL compared to the other ground magnetometer stations presented in Fig. 11 (and the other magnetometers in the SAMNET and IMAGE network not included here) suggests that the oscillations in the solar wind were driving a field line resonance on the Ny Ålesund field line. As can be seen from Fig. 2, this is at the same approximate magnetic latitude as the Cluster and Double Star spacecraft when mapped from their location in the vicinity of the dayside magnetopause. Further analysis reveals that there is little or no latitudinal phase structure in the oscillations with frequencies less than $1 \mathrm{mHz}$ suggesting that these are global modes of oscillation. This is confirmed by the examination of data from the high latitude stations of the 210 Meridian magnetometer chain located some $8 \mathrm{~h}$ of magnetic local time eastward of the Scandinavian sector (not shown). The higher frequency waves observed in the Scandinavian exhibit low, positive azimuthal wave numbers in the range 1-5 and, as such, appear to propagate eastward towards noon. This is consistent with CUTLASS Iceland SuperDARN radar data. These measurements, taken along an eastward pointing beam indicate show $\sim 5$ min period waves modulating the eastward (noonward) plasma flow in the F-region ionosphere. Given the near meridional alignment of the EISCAT VHF radar beam, it is not possible to infer the zonal motion of the phase structure of the $\sim 5$ min fluctuations with any certainty, although there is strong evidence of poleward phase motion.

It is probably impossible to ascribe a definite link between the ULF waves observed in the solar wind and ionosphere with the signatures of magnetic reconnection observed at the magnetopause and in the high-latitude ionosphere. However, it is interesting to note that inter-PIF period observed by the ionospheric radars employed in this study $(\sim 10-15 \mathrm{~min})$ corresponds to the frequency range in which oscillations are present in the solar wind (from ACE data) and magnetosphere (from ground magnetometer data). The inter-FTE period observed at Cluster was much shorter at $\sim 3-4 \mathrm{~min}$, however, the SuperDARN and EISCAT data at this time did not provide sufficient coverage or temporal resolution to quality to investigate any ionospheric signatures of these FTEs.

\section{Conclusions}

Over a three hour interval 06:00-09:00 UT on 25 March 2004, the IMF and solar wind were steady with a strongly duskward orientation and a speed of $\sim 350 \mathrm{~km} \mathrm{~s}^{-1}$. During 
this period, the Double Star TC1 and Cluster spacecraft traversed the dayside magnetopause, Double Star moving inbound from the magnetosheath at low southern latitude and Cluster moving outbound at high northern latitude. The magnetopause traversals all took place at $\sim 13: 00$ MLT but were separated by approximately one hour. While in the magnetosheath/boundary layer, several flux transfer events were observed by both Double Star and Cluster. In each case, these were characterised by bipolar perturbations in the magnetic field component normal to the local magnetopause, enhancements in the total magnetic field strength and evidence of magnetosheath and magnetospheric plasma mixing.

Even though the FTEs were not observed simultaneously at high and low latitudes (with approximately one hour elapsing between the TC1 and Cluster observations) the relatively uniform IMF and solar wind conditions suggested that the reconnection line location and orientation did not change significantly over the intervening interval. This assumption was tested using the Cooling model of flux tube motion over the surface of the magnetopause. The main findings are:

- The direction of plasma flow in the magnetopause boundary layer measured at the Double Star and Cluster spacecraft are generally consistent with magnetic reconnection occurring at a tilted $\mathrm{X}$-line passing through the sub-solar point. Similarly, the direction of motion of FTEs derived from a multi-spacecraft analysis of the bipolar signatures observed by Cluster was consistent with that of a newly-opened flux tube launched from a tilted $\mathrm{X}$-line passing through the sub-solar point.

- Under the prevailing $B_{Y}$ dominated IMF conditions, the Cooling model predicted that Northern Hemisphere flux tubes launched from a subsolar X-line (consistent with the component reconnection model) would engulf the Double Star and Cluster spacecraft. This was entirely consistent with the normal polarity FTEs observed at each spacecraft. Flux tubes originating from an antiparallel reconnection site were not predicted to pass by either Cluster or Double Star. We thus infer that the observed FTEs originated from a low latitude tilted Xline rather than a high latitude anti-parallel X-line.

- While the direction of motion in the plane of the magnetopause was in good agreement, the Cooling model significantly over-estimated the speed of flux tube motion and boundary-layer flow. We note that this is consistent with a recent survey of Cluster data by Longmore et al. (2004) that has reported a deceleration of the magnetosheath flow at higher latitudes close to the magnetopause. This has highlighted an important difference between observations and the gas-dynamic models on which the Cooling model is based. The implications for this increasingly exploited model of open flux tube motion requires further investigation.
- During much of the interval, ground-based measurements in the high latitude dayside ionosphere revealed pulsed ionospheric flows (PIFs) originating from the vicinity of the Cluster and Double Star magnetic footprints. These signatures were accompanied by structured precipitation enhancing the electron density in the F-region ionosphere, observed by the EISCAT Svalbard radar. The PIFs are interpreted as further evidence of ongoing dayside reconnection.

- Throughout the interval there was evidence of ULF oscillations in the solar wind, on magnetospheric field lines and in the ionospheric plasma flow. A range of periodicities were apparent, including fluctuations approximately matching the inter-FTE period observed by ground-based radars, but not the inter-FTE period observed by Cluster in the magnetopause.

Therefore, based upon a simple model of open flux tube motion over the surface of the magnetopause constrained by space- and ground-based measurements of the signatures of flux transfer, we conclude that under strongly duskward IMF conditions, component reconnection was occurring at a tilted $\mathrm{X}$-line passing through the sub-solar region. There was no evidence of reconnection at high latitude, anti-parallel reconnection sites at either the Cluster or Double Star spacecraft. This potent synergy of measurements and modelling thus reveals the likely location and orientation of the reconnection X-line during the period under scrutiny. In an initial study of the same interval based solely on observational data (Wild et al., 2005b) such an inference proved impossible. Therefore, we suggest that the analysis technique described above represents a powerful tool for investigating the location of the reconnection site on the dayside magnetopause. However, despite simultaneous observations of ULF pulsations throughout the solar wind-magnetosphere-ionosphere system, the causal relationship between ULF pulsations and the modulation of the reconnection process remains unclear and will no doubt be the focus of future scrutiny.

Acknowledgements. We thank the ACE Science Center and the EISCAT scientific association for the data presented here. Special thanks are also due to A. Marchaudon and J.-M. Bosqued for preparing the Cluster/Double Star PEACE and CIS data respectively. The CUTLASS HF radars are deployed and operated by the University of Leicester, and are jointly funded by the UK Particle Physics and Astronomy Research Council (PPARC), the Finnish Meteorological Institute, and the Swedish Institute of Space Physics. We also thank the institutes who maintain the IMAGE magnetometer array and the Finnish Meteorological Institute for the provision of the data. SAMNET is a UK National Facility funded by PPARC and operated by Lancaster University. The DOPE experiment is deployed and operated by the University of Leicester and was funded by the Royal Society and PPARC. DMW is supported by a PPARC Advanced Fellowship.

Topical Editor I. A. Daglis thanks Y. Bogdanova and another referee for their help in evaluating this paper. 


\section{References}

Amm, O., Donovan, E. F., Frey, H., Lester, M., Nakamura, R., Wild, J. A., Aikio, A., Dunlop, M., Kauristie, K., Marchaudon, A., McCrea, I. W., Opgenoorth, H. J., and Strømme, A.: Coordinated studies of the Geospace environment using Cluster, satellite and ground-based data: An interim review, Ann. Geophys., 23, 2129-2170, 2005,

http://www.ann-geophys.net/23/2129/2005/.

Balogh, A., Dunlop, M. W., Cowley, S. W. H., Southwood, D. J., Thomlinson, J. G., Glassmeier, K.-H., Musmann, G., Lühr, H., Buchert, S., AcuÜa, M. H., Fairfield, D. H., Slavin, J. A., Riedler, W., Schwingenschuh, K., and Kivelson, M. G.: The Cluster magnetic fields investigation, Space Sci. Rev., 79, 65-91, 1997.

Balogh, A., Carr, C. M., Acuna, M. H., Dunlop, M. W., Beek, T. J., Brown, P., Fornacon, K.-H., Georgescu, E., Glassmeier, K.-H., Harris, J., Musmann, G., Oddy, T., and Schwingenschuh, K.: The Cluster Magnetic Field Investigation: overview of in-flight performance and initial results, Ann. Geophys., 19, 1207-1217, 2001, http://www.ann-geophys.net/19/1207/2001/.

Carr, C., Brown, P., Zhang, T. L., Gloag, J., Horbury, T., Lucek, E., Magnes, W., O’Brien, H., Oddy, T., Auster, U., Austin, P., Aydogar, O., Balogh, A., Baumjohann, W., Beek, T., Eichelberger, H., Fornacon, K. H., Georgescu, E., Glassmeier, K. H., Ludlam, M., Nakamura, R., and Richter, I.: The Double Star magnetic field investigation: instrument design, performance and highlights of the first year's observations, Ann. Geophys., 23, 2713 2732, 2005,

http://www.ann-geophys.net/23/2713/2005/.

Cooling, B. M. A., Owen, C. J., and Schwartz, S. J.: Role of magnetosheath flow in determining the motion of open flux tubes, J. Geophys. Res., 106, 18 763-18 775, 2001.

Cowley, S. W. H. and Lockwood, M.: Excitation and decay of solar wind-driven flows in the magnetosphere-ionosphere system, Ann. Geophys., 10, 103-115, 1992,

http://www.ann-geophys.net/10/103/1992/.

Cowley, S. W. H. and Owen, C. J.: A simple illustrative model of open flux tube motion over the dayside magnetopause, Planet. Space Sci., 37, 1461-1475, 1989.

Crooker, N. U.: Dayside merging and cusp geometry, J. Geophys. Res., 84, 951-959, 1979.

Davies, J. A., Lester, M., and McCrea, I. W.: A statistical study of ion frictional heating observed by EISCAT, Ann. Geophys., 15, 1399-1411, 1997, http://www.ann-geophys.net/15/1399/1997/.

Davies, J. A., Lester, M., and McCrea, I. W.: Solar and seasonal dependence of ion frictional heating, Ann. Geophys., 17, 682691, 1999,

http://www.ann-geophys.net/17/682/1999/.

de Hoffman, F. and Teller, E.: Magneto-hydrodynamic shocks, Phys. Rev., 80, 692, 1950.

Dungey, J. W.: Interplanetary field and the auroral zones, Phys. Res. Lett., 6, 47-48, 1961.

Dunlop, M. W. and Woodward, T. I.: Multi-spacecraft discontinuity analysis: orientation and motion, in: Analysis methods for multispacecraft data, ISSI SR-001, pp. 271-305, ISSI, Bern, Switzerland, 1998.

Dunlop, M. W., Taylor, M. G. G. T., Davies, J. A., Owen, C. J., Pitout, F., Fazakerley, A. N., Pu, Z., Laakso, H., Bogdanova,
Y. V., Zong, Q.-G., Shen, C., Nykyri, K., Lavraud, B., Milan, S. E., Phan, T. D., Rème, H., Escoubet, C. P., abd P. Cargill, C. M. C., Lockwood, M., and Sonnerup, B.: Coordinated Cluster/Double Star observations of dayside reconnection signatures, Ann. Geophys., 23, 2867-2875, 2005,

http://www.ann-geophys.net/23/2867/2005/.

Escoubet, C. P., Schmidt, R., and Goldstein, M. L.: Cluster - science and mission overview, Space Sci. Rev., 79, 391-391, 1997.

Escoubet, C. P., Fehringer, M., and Goldstein, M. L.: The Cluster mission, Ann. Geophys., 19, 1197-1200, 2001, http://www.ann-geophys.net/19/1197/2001/.

Fazakerley, A. N., Carter, P. J., Watson, G., Spencer, A., Sun, Y. Q., Coker, J., Coker, P., Kataria, D. O., Fontaine, D., Liu, Z. X., Gilbert, L., He, L., Lahiff, A. D., Mihaljcic, B., Szita, S., Taylor, M. G. G. T., Wilson, R. J., Dedieu, M., and Schwartz, S. J.: The Double Star Plasma Electron and Current Experiment, Ann. Geophys., 23, 2733-2756, 2005, http://www.ann-geophys.net/23/2733/2005/.

Fedorov, A., Dubinin, E., Song, P., Skalsky, A., and Budnik, E.: Structure of the flank magnetopause for horizontal IMF: INTERBALL 1 observations, J. Geophys. Res., 106, 25 419-25 436, 2001.

Feldstein, Y. I. and Starkov, G. V.: Dynamics of auroral belt and geomagnetic disturbances, Planet. Space Sci., 15, 209-229, 1967.

Gonzalez, W. D. and Mozer, F. S.: A quantitative model for the potential resulting from reconnection with an arbitrary interplanetary magnetic field, J. Geophys. Res., 79, 4186-4194, 1974.

Greenwald, R. A., Baker, K. B., Dudeney, J. R., Pinnock, M., Jones, T. B., Thomas, E. C., Villain, J. P., Cerisier, J. C., Senior, C., Hanuise, C., Hunsucker, R. D., Sofko, G., Koehler, J., Nielsen, E., Pellinen, R., Walker, A. D. M., Sato, N., and Yamagishi, H.: Darn/SuperDARN: a global view of the dynamics of highlatitude convection, Space Sci. Rev., 71, 761-796, 1995.

Haerendel, G., Paschmann, G., Sckopke, N., Rosenbauer, H., and Hedgecock, P. C.: The frontside boundary layer of the magnetopause and the problem of reconnection, J. Geophys. Res., 83, 3195-3216, 1978.

Johnstone, A. D., Alsop, C., Burge, S., Carter, P. J., Coates, A. J., Coker, A. J., Fazakerley, A. N., Grande, M., Gowen, R. A., Gurgiolo, C., Hancock, B. K., Narheim, B., Preece, A., Sheather, P. H., Winningham, J. D., and Woodliffe, R. D.: PEACE: A Plasma Elctron And Current Instrument, Space Sci. Rev., 79, 351-398, 1997.

Khotyaintsev, Y., Buchert, S., Stasiewicz, K., Vaivads, A., Savin, S., Papitashvili, V. O., Farrugia, C. J., Popielawska, B., and Tung, Y. K.: Transient reconnection in the cusp during strongly negative IMF $B_{Y}$, J. Geophys. Res., 109, A04 204, doi:10.1029/2003JA009908, 2004.

Kobel, E. and Flückiger, E. O.: A model of the steady state magnetic field in the magnetosheath, J. Geophys. Res., 99, 23 617-23 622, 1994.

Lester, M., Chapman, P., Cowley, S., Crooks, S., Davies, J., Hamadyk, P., McWilliams, K., Milan, S., Parsons, M., Payner, D., Thomas, E., Thornhill, J., Wade, N., Yeoman, T., and Barnes, R.: Stereo CUTLASS - A new capability for the SuperDARN HF radars, Ann. Geophys., 22, 459-473, 2004, http://www.ann-geophys.net/22/459/2004/.

Liu, Z. X., Escoubet, C. P., Pu, Z., Laakso, H., Shi, J. K., Shen, C., and Hapgood, M.: The Double Star mission, Ann. Geophys., 23, 
2707-2712, 2005,

http://www.ann-geophys.net/23/2707/2005/.

Longmore, M., Schwartz, S. J., Geach, J., Cooling, B. M. A., Dandouras, I., Lucek, E. A., and Fazakerley, A. N.: Dawn-dusk asymmetries and sub-Alfvt'enic flow in the high and low latitude magnetosheath, Ann. Geophys., 23, 3351-3364, 2004, http://www.ann-geophys.net/23/3351/2004/.

Luhmann, J., Walker, R. J., Russell, C. T., Crooker, N. U., Spreiter, J. R., and Stahara, S. S.: Patterns of potential magnetic field merging sites on the dayside magnetopause, J. Geophys. Res., 89, 1739-1742, 1984.

Lühr, H., Aylward, A., Buchert, S. C., Pajunpää, A., Pajunpää, K., Holmboe, T., and Zalewski, S. M.: Westward moving dynamic substorm features observed with the IMAGE magnetometer network and other ground-based instruments, Ann. Geophys., 16, 425-440, 1998,

http://www.ann-geophys.net/16/425/1998/.

McComas, D. J., Bame, S. J., Barker, P., Feldman, W. C., Phillips, J. L., Riley, P., and Griffee, J. W.: Solar Wind Electron Proton Alpha Monitor (SWEPAM) for the Advanced Composition Explorer, Space Sci. Rev., 86, 563-612, 1998.

Owen, C. J., Fazakerley, A. N., Carter, P. J., Coates, A. J., Krauklis, I. C., Szita, S., Taylor, M. G. G. T., Travnicek, P., Watson, G., Wilson, R. J., Balogh, A., and Dunlop, M. W.: Cluster PEACE observations of electrons during magnetospheric flux transfer events, Ann. Geophys., 19, 1509-1522, 2001, http://www.ann-geophys.net/19/1509/2001/.

Pinnock, M., Rodger, A. S., Dudeney, J. R., Rich, F., and Baker, K. B.: High spatial and temporal resolution observations of the ionospheric cusp, Ann. Geophys., 13, 919-925, 1995, http://www.ann-geophys.net/13/919/1995/.

Prikryl, P., Greenwald, R. A., Sofko, G. J., Villain, J. P., Ziesolleck, C. W. S., and Friis-Christensen, E.: Solar-wind-driven pulsed magnetic reconnection at the dayside magnetopause, Pc5 compressional oscillations, and field line ressonances, J. Geophys. Res., 103, 17 307-17 322, 1998.

Provan, G., Yeoman, T. K., and Milan, S. E.: CUTLASS Finland radar observations of the ionospheric signatures of flux transfer events and the resulting plasma flows, Ann. Geophys., 16, 14111422, 1998,

http://www.ann-geophys.net/16/1411/1998/.

Rae, I. J., Fenrich, F. R., Lester, M., McWilliams, K. A., and Scudder, J. D.: Solar wind modulation of cusp particel signatures and their associated ionospheric flows, J. Geophys. Res., 109, A03223, doi:10.1029/2003JA010188, 2004.

Rème, H., Bosqued, J.-M., Sauvaud, J.-A., Cros, A., Dandouras, J., Aoustin, C., Bouyssoua, J., Camus, T., Cuvilo, J., Martz, C., MńEdale, J. L., Perrier, H., Romefort, D., Rouzaud, J., D’uston, C., Möbius, E., Crocker, K., Granoff, M., Kistler, L. M., Popecki, M., Hovestadt, D., Klecker, B., Paschmann, G., Scholer, M., Carlson, C. W., Curtis, D. W., Lin, R. P., Mcfadden, J. P., Formisano, V., Amata, E., Bavassano-Cattaneo, M. B., Baldetti, P., Belluci, G., Bruno, R., Chionchio, G., Lellis, A. D., Shelley, E. G., Ghielmetti, A. G., Lennartsson, W., Korth, A., Rosenbauer, H., Lundin, R., Olsen, S., Parks, G. K., McCarthy, M., and Balsiger, H.: The Cluster Ion Spectrometry (CIS) Experiment, Space Sci. Rev., 79, 303-350, 1997.

Rème, H., Aoustin, C., Bosqued, J.-M., Dandouras, I., Lavraud, B., Sauvaud, J.-A., Barthe, A., Bouyssou, J., Camus, T., Coeur-Joly,
O., Cros, A., Cuvilo, J., Ducay, F., Garbarowitz, Y., Medale, J. L., Penou, E., Perrier, H., Romefort, D., Rouzaud, J., Vallat, C., Alcaydé, D., Jacquey, C., Mazelle, C., d'Uston, C., Möbius, E., Kistler, L. M., Crocker, K., Granoff, M., Mouikis, C., Popecki, M., Vosbury, M., Klecker, B., Hovestadt, D., Kucharek, H., Kuenneth, E., Paschmann, G., Scholer, M., Sckopke, N., Seidenschwang, E., Carlson, C. W., Curtis, D. W., Ingraham, C., Lin, R. P., McFadden, J. P., Parks, G. K., Phan, T., Formisano, V., Amata, E., Bavassano-Cattaneo, M. B., Baldetti, P., Bruno, R., Chionchio, G., Lellis, A. D., Marcucci, M. F., Pallocchia, G., Korth, A., Daly, P. W., Graeve, B., Rosenbauer, H., Vasyliunas, V., McCarthy, M., Wilber, M., Eliasson, L., Lundin, R., Olsen, S., Shelley, E. G., Fuselier, S., Ghielmetti, A. G., Lennartsson, W., Escoubet, C. P., Balsiger, H., Friedel, R., Cao, J.-B., Kovrazhkin, R. A., Papamastorakis, I., Pellat, R., Scudder, J., and Sonnerup, B.: First multispacecraft ion measurements in and near the Earth's magnetosphere with the identical Cluster ion spectrometry (CIS) experiment, Ann. Geophys., 19, 1303-1354, 2001, http://www.ann-geophys.net/19/1303/2001/.

Rème, H., Dandouras, I., Aoustin, C., Bosqued, J. M., Sauvaud, J. A., Vallat, C., Escoubet, P., Cao, J. B., Shi, J., BavassanoCattaneo, M. B., Parks, G. K., Carlson, C. W., Pu, Z., Klecker, B., Kistler, E. M., Korth, A., Lundin, R., and the HIA team: The HIA instrument on board the Tan Ce 1 Double Star near-equatorial spacecraft and its first results, Ann. Geophys., 23, 2757-2774, 2005 ,

http://www.ann-geophys.net/23/2757/2005/.

Rijnbeek, R. P., Cowley, S. W. H., Southwood, D. J., and Russell, C. T.: A survey of dayside flux transfer events observed by ISEE 1 and 2 magnetometers, J. Geophys. Res., 89, 786-800, 1984.

Rishbeth, H. and van Eyken, A. P.: EISCAT: early history and the first ten years of operation, J. Atmos. Terr. Phys., 55, 525-542, 1993.

Ruohoniemi, J. M. and Baker, K. B.: Large-scale imaging of highlatitude convection with Super Dual Auroral Radar Network HF radar observations, J. Geophys. Res., 103, 20 797-20 811, 1998.

Ruohoniemi, J. M. and Greenwald, R. A.: Statistical patterns of high-latitude convection obtained from Goose Bay HF radar observations, J. Geophys. Res., 101, 21 746-21 763, 1996.

Russell, C. T. and Elphic, R. C.: Initial ISEE magnetometer results: magnetopause observations, Space Sci. Rev., 22, 681-715, 1978.

Russell, C. T. and Elphic, R. C.: ISEE observations of flux transfer events at the dayside magnetopause, Geophys. Res. Lett., 6, 3336, 1979.

Sandholt, P. E. and Farrugia, C. J.: Spatiotemporal structure of the reconnecting magnetosphere under B-y-dominated interplanetary magnetic cloud conditions, J. Geophys. Res., 111, A10 209, doi:10.1029/2005JA011514, 2006.

Shue, J.-H., Chao, J. K., Fu, H. C., Russell, C. T., Song, P., Khurana, K. K., , and Singer, H. J.: A new functional form to study the solar wind control of the magnetopause size and shape, J. Geophys. Res., 102, 9497-9511, 1997.

Smith, C. W., na, M. H. A., Burlaga, L. F., L'Heureux, J., Ness, N. F., and Scheifele, J.: The ACE Magnetic Fields Experiment, Space Sci. Rev., 86, 613-631, 1998.

Spreiter, J. R., Sumers, A. L., and Alksne, A. Y.: Hydrodynamic flow around the magnetosphere, Planet. Space Sci., 14, 223-253, 1966. 
Stone, E. C., Frandsen, A. M., Mewaldt, R. A., Christian, E. R., Marglies, D., Ormes, J. F., , and Snow, F.: The Advanced Composition Explorer, Space Sci. Rev., 86, 1-22, 1998.

Trattner, K. J., Petrinec, S. M., Peterson, W. K., Fuselier, S. A., and Rème, H.: Tracing the location of the reconnection site from the northern and southern cusps, J. Geophys. Res., 111, A11 211, doi:10.1029/2006JA01167, 2006.

Wild, J. A., Cowley, S. W. H., Davies, J. A., Khan, H., Lester, M., Milan, S. E., Provan, G., Yeoman, T. K., Balogh, A., Dunlop, M. W., Fornacon, K.-H., and Georgescu, E.: First simultaneous observations of flux transfer events at the high-latitude magnetopause by the Cluster spacecraft and pulsed radar signatures in the conjugate ionosphere by the CUTLASS and EISCAT radars, Ann. Geophys., 19, 1491-1508, 2001, http://www.ann-geophys.net/19/1491/2001/.

Wild, J. A., Milan, S. E., Cowley, S. W. H., Bosqued, J. M., Rème, H., Nagai, T., Kokubun, S., Saito, Y., Mukai, T., Davies, J. A., Cooling, B. M. A., Balogh, A., and Daly, P. W.: Simultaneous insitu observations of the signatures of dayside reconnection at the high and low latitude magnetopause, Ann. Geophys., 23, 445460, 2005a.
Wild, J. A., Milan, S. E., Davies, J. A., Cowley, S. W. H., Carr, C. M., and Balogh, A.: Double Star, Cluster, and groundbased observations of magnetic reconnection during an interval of duskward oriented IMF: preliminary results, Ann. Geophys., 23, 2903-2907, 2005b.

Wing, S., Newell, P. T., and Ruohoniemi: Double cusp: Model prediction and observational verification, J. Geophys. Res., 106, 25 571-25 593, 2001.

Wing, S., Newell, P. T., and Meng, C.-I.: Cusp modeling and observations at low altitude, Surv. Geophys., 26, 341-367, 2005.

Wright, D. M., Yeoman, T. K., and Chapman, P. J.: High-latitude HF Doppler observations of ULF waves. 1. Waves with large spatial scale sizes, Ann. Geophys., 15, 1548-1556, 1997, http://www.ann-geophys.net/15/1548/1997/.

Yeoman, T. K., Milling, D. K., and Orr, D.: Pi2 pulsation polarization patterns on the U.K. sub-auroral magnetometer network (SAMNET), Planet. Space Sci., 38, 589-602, doi:10.1016/0032-0633(90)90065-X, 1990.

Yeoman, T. K., Wright, D. M., Chapman, P. J., and StocktonChalk, A. B.: High-latitude observations of ULF waves with large azimuthal wavenumbers, J. Geophys. Res., 105, 54535462, doi:10.1029/1999JA005081, 2000. 